\title{
Mechanical behavior of annealed electrochemically deposited nanocrystalline nickel-iron alloys
}

\author{
Joachim E. Hoffmann, Martin-T. \\ Schmitt, Dietmar Eifler, Tilmann \\ Beck, Torsten Hielscher, Tina \\ Eyrisch, Peter Starke, Kaiserslautern, \\ Germany, Monika Saumer, \\ and Patrick Klär, Zweibrücken, \\ Germany
}

Nanocrystalline nickel-iron layers are produced electrochemically on copper discs by varying the current density and then annealed in a vacuum furnace at a temperature range between 200 and $800{ }^{\circ} \mathrm{C}$. Grain size, iron content, texture and microstrain of the microstructure are primarily characterized by X-ray diffraction (XRD). Instrumented indentation tests and microbending tests for mechanical characterization are carried out. The iron contents of the investigated layers are 5.7, 8.8, 13.5 and $17.7 \mathrm{wt} . \mathrm{\%}$. By varying the annealing temperature, the reduction of the microstrains is initiated at $200{ }^{\circ} \mathrm{C}$ and ends at a temperature of about $280^{\circ} \mathrm{C}$. Primary recrystallization starts slightly higher at $220^{\circ} \mathrm{C}$ and is completed at $300^{\circ} \mathrm{C}$. With higher iron content, the indicated temperatures shift to slightly higher values. Indentation modulus, Young's modulus, indentation hardness and strength change considerably after the annealing treatment. Fracture strain at the edge, as a measure of ductility, decreases immediately after annealing at $200{ }^{\circ} \mathrm{C}$ to $0 \%$. Low annealing temperatures occurring before the beginning of primary recrystallization lead to an increase in indentation hardness and 0.01-\% offset bending yield strength $\mathrm{R}_{\mathrm{p} 0.01}{ }^{*}$ as compared to the electrochemically deposited initial state. After annealing at high temperatures, the mechanical parameters are mostly below the initial values for electrochemical deposition. Hall-Petch (HP) behavior is observed for $\mathrm{R}_{\mathrm{p} 0.01}{ }^{*}$, both for the electrochemically deposited specimens down to almost $6 \mathrm{~nm}$ and for the specimens annealed at high temperatures. Specimens annealed at low temperatures deviate from the HP straight line to higher values. In this case, an increase in strength is assumed to be due to the very small nanocrystalline (nc) grain sizes, segregation at the grain boundaries and a decrease in dislocation density. Indentation hardness measurements show almost no dependence on $\mathrm{D}^{-0.5}$ for the electrochemically deposited specimens and also for annealed specimens below $30 \mathrm{~nm}$ grain size. Above $30 \mathrm{~nm}$, the indentation hardness values are considerably higher than for the HP straight line. Overall, the hardness and strength values of the nc specimens, electrochemically deposited or additionally annealed, are significantly higher than those of the microcrystalline $(\mathrm{mc})$ specimens.
Nanocrystalline material with grain sizes smaller than $100 \mathrm{~nm}$ [1-3] exhibits excellent mechanical as well as physical proper- ties. Extremely high strength and hardness values can be realized which considerably exceed those of conventional coarser- grained materials [2-8]. The hardness and strength values are 2 to 10 times higher than for conventional microcrystalline ma- 
terials with grain sizes in the $\mu \mathrm{m}$ range (grain size $\mathrm{D}>1 \mu \mathrm{m})$. Often, however, only low ductility and very poor thermodynamic stability appear for nc materials.

The preparation of nc material is carried out using so-called "bottom up" or "top down" processes [2-4]. "Top down” processes convert conventional crystalline microstructures (grain sizes D $>1 \mu \mathrm{m}$ ) into ultrafine crystalline (ufg, $100 \mathrm{~nm}<\mathrm{D}<1000 \mathrm{~nm}$ ) or nanocrystalline $(\mathrm{D}<100 \mathrm{~nm})$ microstructures by severe plastic deformation (SPD). The "bottom up" processes include electrochemical deposition and physical vapor deposition. Deposition technology offers the possibility of producing only thin layers as well as complex micro-components. LIGA technology (lithography, electroplating and molding) or the direct LIGA process can be used to produce high-precision micro-components with a high aspect ratio (component height to width), e.g. microgears for micro-electromechanical systems (MEMS) [9]. Microgears have excellent mechanical properties due to their nc microstructure [10].

Electrochemical metal deposition offers many influencing parameters to modify the microstructure and thus the material properties. These include a bath composition (metal salt type, $\mathrm{pH}$ value, concentration of metal ions, additives), bath process parameters (e.g. temperature, electrolyte motion), and current parameters (e.g. current density, current-time function) [3, 4, 11, 13]. Compared to electroplated films, LIGA micro-components are deposited in prepatterned polymer structures influencing the local current density and thus result in differences in microstructure and local properties of the material both for lateral and vertical orientation [10,11].

Due to their mechanical, soft magnetic and chemical properties at room temperature, nickel or nickel alloys often belong to the materials choosen for the production of miniaturized structures for MEMS [11-15]. Defined microstructure parameters as chemical composition, grain size, grain structure, twin density, textures, residual stress and micr-strains as well as specific material properties can be designed and provided by controlling the electrochemical process parameters $[3,10,16]$. The iron content of nickel-iron alloys is, for example, adjustable with respect to current density and the electrolyte composition [3, 10, 11, 16].

The grain size in layers of pure nickel decreases from about $200 \mathrm{~nm}$ to $25 \mathrm{~nm}$ when the current density increases from 1 to $10 \mathrm{~A} \times \mathrm{dm}^{-2}$ [12]. In the case of nickel- iron alloys, the trend is reversed, where increasing current density ranges for $\mathrm{ex}^{-}$ ample from 6 to $15 \mathrm{~A} \times \mathrm{dm}^{-2}$ or from 0.2 to $10 \mathrm{~A} \times \mathrm{dm}^{-2}$, with the grain size increasing

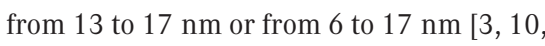
13]. Nickel-iron alloys also have smaller grains than pure nickel at the same current density. The cause for this is a higher nucleation rate in nickel-iron than in nickel. With increasing current density, however, the iron content in the electrolyte and thus the nucleation rate decreases and the grain size increases. With pulse current deposition in contrast to direct current deposition, higher current densities and thus smaller grains below $20 \mathrm{~nm}$, without pores and without textures can be provided due to short pulse durations in the millisecond range. Moreover, the use of additives reduces grain size during electrochemical deposition $[4,17,18]$. The particle size distribution of electrochemical deposition is relatively narrow.

Additives, such as sulphur-containing bath additives (e.g. saccharin) are used as brighteners in the deposition of nickel or nickel-iron layers [10, 16, 19-21]. They also avoid the formation of residual tensile stress. Without additives, cracks in the layers are possible due to high tensile residual stress $[10,19,20]$. However, the sulphur compounds of the decomposition products of the additives can also have an adverse effect on ductility similar to impurities [10, 16, 19, 20].

During electrochemical deposition, textures are usually formed. For nickel layers these are fiber textures in the directions $\langle 100\rangle,\langle 110\rangle,\langle 210\rangle$ and <211> [22]. By adding saccharin, nickel and nickel-iron alloys form double $\langle 100\rangle$-, $\langle 111\rangle$-fiber textures [3, 10, 17, 18]. With an increase in iron content, the <111>-texture increases at the expense of the $<100>$-texture [23].

Microstrains or lattice strains as local inhomogeneous strains are the result of local defects such as dislocations, voids, twins or foreign atoms. They are also influenced by the process parameters. An increase in iron content, for example, causes increasing microstrains in electrochemically deposited nickel-iron layers [3, 10, 24]. Increasing current density leads to decreasing microstrains in nickel-iron alloys and to increasing microstrains in pure nickel layers [3, 10, 18].

Compared to conventional mc microstructures, nanocrystals exhibit extremely high yield strength, tensile strength and micro-hardness. The relation between grain size D and yield strength,
$\mathrm{R}_{\mathrm{eS}}=\sigma_{0}+\frac{\mathrm{k}_{\sigma}}{\sqrt{\mathrm{D}}}$

as well as the indentation hardness,

$\mathrm{H}_{\mathrm{IT}}=\mathrm{H}_{0}+\frac{\mathrm{k}_{\mathrm{H}}}{\sqrt{\mathrm{D}}}$

are assigned as the Hall-Petch equation [2$4,7,10,15,22-25] . \sigma_{0}$ and $k_{\sigma}$ as well as $H_{0}$ and $\mathrm{k}_{\mathrm{H}}$ are material-dependent constants. Depending on the strain rate, deviating or an inverse Hall-Petch behavior is often observed in grain sizes smaller than $20 \mathrm{~nm}$ [2, 7, 15, 25-27]. Consequently, strength and hardness increase less with decreasing grain size up to a local maximum and decrease for even smaller grains due to the softening effects of the material. Our own investigations show the Hall-Petch behavior for grain size down to about $6 \mathrm{~nm}$, but only for yield strength and not for indentation hardness and also not for bending strength [3, 10]. A variation in the strain rate, between 0.1 and $0.000001 \mathrm{~s}^{-1}$, had only a small effect in these investigations.

Further factors influencing the strength of nc material are solid solution atoms, dislocations, precipitates and textures. The Hall-Petch straight line is shifted, for example, to higher values compared to pure nickel $[15,24]$. In another work, the slope $\mathrm{k}$ of the Hall-Petch straight line depending on the texture is examined more closely with respect to grain size distribution [22].

The deformation behavior of nc metals is explained by two competing physical mechanisms related to grain size [22, 28]. Dislocation slippage predominates in nanocrystals with larger grain diameters, and deformation takes place as common for conventional materials. Grain boundaries are an obstacle for dislocation slippage and have a strengthening effect due to dislocation accumulation. The Hall-Petch relationship applies in this case. In very small nanocrystals, for a critical grain size below 20 or 10 or down to $6 \mathrm{~nm}$ for pure nickel [3, $15,24,29]$, there is no possibillity for sliding dislocations. Frank Read sources for generating dislocations within the grains require too high stress. Then grain boundary deformation mechanisms such as the initiation of dislocations at the grain boundaries, grain boundary slip or Coble creep increasingly dominate deformation behavior $[15,28,30]$. It might be noted that the transition of the deformation mechanisms considered from dislocation sliding to grain boundary sliding depends on the strain rate. 
Low elongation to fracture in nc metals, which is often less than $2 \%$, is considered to be caused by artifacts in the manufacturing process $[2,5,8]$. Artefacts are impurities, pores, faulty bonds and larger microstrains. Artifact-free nickel and $\mathrm{Ni}-15 \% \mathrm{Fe}$, electrochemically deposited without the use of additives, exhibit excellent strength values at a certain ductility of up to $10 \%$ [31]. Nickel with a grain size of $44 \mathrm{~nm}$ and $\mathrm{Ni}-15 \% \mathrm{Fe}$ with a grain size of $9 \mathrm{~nm}$ are relatively ductile with $9.5 \%$ and $6 \%$ elongation at fracture, but differ in their plastic deformation and type of fracture depending on grain size. The larger nanocrystals of nickel above the critical grain size are deformed like conventional metals by dislocation sliding with the constriction of the specimen. Below critical grain size, grain boundary sliding is observed in very small nanocrystals from Ni-15\% Fe, with failure from grain boundary cracks without a significant reduction in area [5, 31]. Superplastic deformation and creep behavior at room temperature of electrochemically deposited nc pure copper with a grain size of about $30 \mathrm{~nm}$ is also explained by grain boundary deformation mechanisms [8]. An evaluation of the ductility of nanocrystalline metals shows that despite a low elongation at fracture, a local reduction in area as well as pitting and also ductile deformation behavior can occur [30].

Due to extremely small grain size and the resulting high grain boundary volume, the thermal stability of the microstructure of nanocrystalline materials is considerably lower than that of conventional materials [7, 15, 23, 32]. For example, the grain boundary volume of a grain size of $5 \mathrm{~nm}$ is in the order of $50 \%$ [28, 32]. At relatively low annealing temperatures, high grain boundary energy causes a reduction in micro-strain and grain growth at slightly higher temperatures. Nucleation and abnormal grain growth are determined by differential thermal analysis (DTA) or transmission electron microscopy (TEM) for pure nc nickel with a grain size from 10 to $20 \mathrm{~nm}$ at $80^{\circ} \mathrm{C}$ and $120^{\circ} \mathrm{C}$, respectively [32]. Abnormal/bimodal grain growth means the growth of a few grains in the surrounding nanocrystalline structure. Nickel-iron alloys exhibit improved thermal stability and higher grain growth temperatures than pure nickel $[7,15]$. Ni15 wt-.\% Fe, deposited electrochemically without saccharin, with average grain sizes of $12 \mathrm{~nm}$ or $17 \mathrm{~nm}$, measured by Xray diffraction (XRD) or TEM, shows a slight increase in grain size to $14 \mathrm{~nm}$
(XRD) or $62 \mathrm{~nm}$ (TEM) only after annealing at $250^{\circ} \mathrm{C}, 1 \mathrm{~h}$ [7]. Considerable grain growth is achieved by annealing at $400{ }^{\circ} \mathrm{C}$, $1 \mathrm{~h}$ or $500^{\circ} \mathrm{C}, 1 \mathrm{~h}$ to $152 \mathrm{~nm}$ or $559 \mathrm{~nm}$ (TEM). Ni-50 wt.-\% Fe manifests better thermal stability than Ni-21 wt.-\% Fe [23, 33]. The lower thermal stability of $\mathrm{Ni}-$ $21 \mathrm{wt}-$ \% Fe is caused by lower iron content and the smaller initial grain size as well as a lower contamination through sulphur (without additives) [23].

After electrochemical deposition at various current densities and a variation of saccharin content, varied grain sizes of 10 to $98 \mathrm{~nm}$ in nanocrystalline nickel specimens can be realized [34]. Due to the use of saccharin additive, nickel with a grain size of $10 \mathrm{~nm}$ shows an abnormal grain growth from $317^{\circ} \mathrm{C}$ and strongly decreasing thermal stability. Stress relaxation for this grain size is determined from $60^{\circ} \mathrm{C}$ onwards. Larger nickel grains (grain sizes 28 to $98 \mathrm{~nm}$ ) require a considerably higher temperature of $600{ }^{\circ} \mathrm{C}$ to grow. The reason for the relatively high grain growth temperatures of nc nickel is presumably the saccharin content, the temperature-time profile without interruptions during the heating process (heating rate: $10{ }^{\circ} \mathrm{C} \times \mathrm{min}^{-1}$ from 50 to $700^{\circ} \mathrm{C}$ ) in the DTA as well as the larger grains.

Textures and their effects on the thermal stability of nickel/nickel-iron alloys have been considered comparatively little so far [35]. Electrochemically deposited $\mathrm{Ni}-$ 21 wt. $\%$ Fe with double $<100>-,<111>$-fiber texture and a dominant <111>-portion shows a decreasing orientation of the crystals with an increasing annealing temperature from 100 to $500{ }^{\circ} \mathrm{C}$ [23]. These results are in accordance with electrochemically deposited Ni-50\% Fe where after annealing at $400{ }^{\circ} \mathrm{C}$ a declining texture is observed [33]. In contrast to this finding, for $\mathrm{Ni}-$ 45 wt. $\%$ Fe with $<111>-$-oriented grains the texture increases by annealing at 400 and $500{ }^{\circ} \mathrm{C}$ [36]. These contradictory results can be explained through differences in impurities, grain size and texture after electrochemical deposition [23]. During the pulsed laser deposition of nickel, increasing substrate temperature leads from randomly distributed grains to pronounced $<100>$-oriented grains [35]. $<100>$-oriented grains increase the thermal stability of the deposited material. The change in texture as well as grain growth also depends on the annealing time.

The microstrains or lattice strains (XRD analyses) of electrochemically deposited nc nickel or nickel-iron alloys are more or less reduced even at very low annealing temperatures [7, 23, 37]. At these temperatures, however, no grain growth and no change in grain structure occurs. Nickel reduces its microstrain at $100{ }^{\circ} \mathrm{C}, 1 \mathrm{~h}$ from 0.313 to $0.211 \%$ [37]. For Ni-21 wt.-\% Fe, however, only a slight decrease from 0.29 to $0.27 \%$ is observed after annealing at $100{ }^{\circ} \mathrm{C}, 90 \mathrm{~min}$ [23]. After annealing at a higher temperature of $500{ }^{\circ} \mathrm{C}$, microstrains are reduced by $90 \%$. Ni- 15 wt.- $\%$ Fe with lower iron content results in a stronger decrease in the lattice strain from $0.208 \%$ after electrochemical deposition to $0.106 \%$ after annealing at $250{ }^{\circ} \mathrm{C}, 90 \mathrm{~min}$. If this material is annealed at a temperature of $400{ }^{\circ} \mathrm{C}$, the lattice strain drops down to $0 \%$ [7].

With the various measurement methods, differences can occur in the results of the characteristic conditions. XRD and TEM analyses, for example, provide a mean grain size with a relatively narrow grain size distribution after the electrochemical deposition of nickel or nickel-iron alloys of approx. equal values, e.g. 13 and $11 \mathrm{~nm}$ (XRD and TEM) [23] or $16 \mathrm{~nm}$ (XRD) and $19 \mathrm{~nm}$ (TEM) [33]. By contrast, after annealing at $190^{\circ} \mathrm{C}, 720 \mathrm{~min}$ there are differences in the mean values determined from XRD and TEM, e.g. $32 \mathrm{~nm}$ (XRD) and $37 \mathrm{~nm}$ (TEM) for the normal grain size and $190 \mathrm{~nm}$ (TEM) for the abnormal grain size [33]. TEM can therefore be used to differenciate normal and abnormal grain size distributions resulting in mean values which are different from those obtained by XRD measurements [7, 33, 38]. Using results from TEM and atom probe tomography (APT), DTA curves provide further information regarding the temperature ranges of recovery processes, deposition of dissolved atoms to grain boundaries and precipitationing of phases, normal and abnormal grain growth, and activation energy for grain growth of nc materials [39].

The mechanical behavior of nc nickel specimens electrochemically deposited with additives (e.g. saccharin) and annealed can be classified into three ranges [37]. Range I is characterized by a low-temperature annealing process up to 150 and $200{ }^{\circ} \mathrm{C}$, respectively $[37,39]$. As a result from the recovery processes, there is an increase in hardness and strength [37] as well as a slight reduction in the elongation at fracture compared with the electrochemically deposited state without annealing. Pitting features on the fracture surfaces confirm a ductile fracture behavior. Nc alloys, such as pure nc metals deposited with additives, exhibit a strength increase by 
annealing, but only at higher temperatures $[7,15,38]$. The increase in strength is caused by a decrease in dislocation density and dislocation sources at the grain boundaries, the redistribution of very fine atomic impurities from the inner part of the grains to the boundaries (e.g. sulphur from saccharin) as well as decreasing microstrains $[7,15,37]$. After annealing, there are no dislocations within the grains of the nc metals and only a few at the grain boundaries [29, 40]. Grain boundaries are the main sources of dislocations for mechanisms leading to plastic deformation. A lower amount of dislocations, however, require higher stress and increases the strength of the nc material. Impurities can further limit the formation and movement of dislocations at the grain boundaries and anchor them. These are further reasons for decreasing ductility, but these appear noticeably only from 200 to $250^{\circ} \mathrm{C}$. Only in very pure electrochemically deposited nc metals (without additives) can strengthening by annealing be avoided [41].

Within Range II, local grain growth starts with abnormal or a bimodal (dual) grain distribution. For this incipient primary recrystallization, the temperatures determined for nc nickel are fairly low and may also differ significantly, e. g. from 80 and $120^{\circ} \mathrm{C}$ (without additives), respectively [32], at $200^{\circ} \mathrm{C}$ (with saccharin) [33, 37] or at $317^{\circ} \mathrm{C}$ (with saccharin) [34]. The growth of individual grains can be explained by inhomogeneous microstructures at the grain boundaries received from annealing [42]. Grain growth inhibitors, such as impurities, pores or uneven grain boundary structures, are randomly distributed at the grain boundaries. Where growth inhibitors are lacking, local grain growth may occur due to high grain boundary energy and high grain boundary mobility present there. During the annealing process, a microstructure is formed consisting of two portions; individual larger grains are embedded in a surrounding nanocrystalline matrix. After annealing nc nickel at $200{ }^{\circ} \mathrm{C}$, such abnormal/bimodal grain size distributions may exhibit improved tensile properties, namely good strength due to the nc grains with increased ductility caused by the larger grains [30, 37].

In the Range III, from about $250^{\circ} \mathrm{C}$, the ductility of nc nickel or nickel-iron alloys decreases towards zero and the strength or hardness drops considerably [7, 15, 23, 33, $37,41]$. The diffusion of impurities such as sulphur is orders of magnitude higher than the self-diffusion of nickel. Noticeable impurities at the grain boundaries result in fracture surfaces with intergranular cleavage fracture and brittle behavior. After annealing treatments at 250 or $300{ }^{\circ} \mathrm{C}$, sulphur depositions of up to about 7 wt.-\% are determined at some locations of the grain boundaries $[33,37]$. With nc nickel, abnormal grain growth is replaced by normal grain growth at temperatures higher than 290 or $320^{\circ} \mathrm{C}$ $[32,33]$. Grain growth towards equilibrium is observed for 370 to $500{ }^{\circ} \mathrm{C}$ [32]. With nickel alloys, the corresponding temperatures shift to higher values.

After annealing treatments with increasing annealing temperatures for nc nickel alloys, electrochemically deposited, a maximum hardness is achieved. At even higher annealing temperatures, hardness values decrease [7, 15, 29, 37, 38, 41]. E. g., Ni-1 at. $\%$ Fe deposited with saccharin shows an unchanged microhardness of $5.95 \mathrm{GPa}$ [41] after annealing up to $176^{\circ} \mathrm{C}$, $1 \mathrm{~h}$. After annealing at $206^{\circ} \mathrm{C}, 1 \mathrm{~h}$, a still low maximum hardness of $6.14 \mathrm{GPa}$ is obtained. After annealing up to $256^{\circ} \mathrm{C}, 1 \mathrm{~h}$, the hardness drops sharply down to $3.62 \mathrm{GPa}$, and up to $526^{\circ} \mathrm{C}, 1 \mathrm{~h}$ to about $3.4 \mathrm{GPa}$. A mean grain size of $14.6 \mathrm{~nm}$ (XRD) and a microstrain of $0.41 \%$ are approx. constant up to an annealing temperature of $206^{\circ} \mathrm{C}$. Thus, microhardness increases slightly up to maximum hardness before grain growth by annealing occurs. After annealing at $276{ }^{\circ} \mathrm{C}, 1 \mathrm{~h}$, microstrain is negligibly small and grain size at about $90 \mathrm{~nm}$. For increasing annealing times, hardness decreases continuously, reaching $3.88 \mathrm{GPa}$ after 48 hours. After annealing at $206^{\circ} \mathrm{C}, 2 \mathrm{~h}$ and $10 \mathrm{~h}$, abnormal/bimodal grain size distributions are determined by means of TEM.

Electrochemically deposited nickel-molybdenum alloys show decreasing average grain sizes with increasing molybdenum content, starting from $30 \mathrm{~nm}$ for pure nickel to $3.4 \mathrm{~nm}$ (TEM) for Ni-21.5 at.-\% Mo [29]. Pure nc nickel with a hardness of $4.34 \mathrm{GPa}$ reaches a maximum hardness of $4.91 \mathrm{GPa}$ after annealing at $200^{\circ} \mathrm{C}, 1 \mathrm{~h}$ without considerable changes in grain size. Annealing at even higher temperatures causes a decrease in hardness to $2.36 \mathrm{GPa}$ at $400{ }^{\circ} \mathrm{C}, 1 \mathrm{~h}$. By adding molybdenum up to 21.5 at. $\%$, the Vickers hardness increases to $5.02 \mathrm{GPa}$. Additional annealing of this alloy results in a strong increase in hardness up to a maximum hardness of $11.35 \mathrm{GPa}$ at $525^{\circ} \mathrm{C}, 1 \mathrm{~h}$. The molybdenum content increases the annealing temperature for which maximum hardness is achieved and hence improves thermal stability. Only at this annealing temperature does the grain growth of the nanoparticles begin and the Vickers hardness decrease noticeably.

The mechanical behavior of electrochemically deposited nc nickel and nc nickeliron after various annealing treatments, between 100 and $600{ }^{\circ} \mathrm{C}$, follows the HallPetch straight line for yield strength [7, 23] as well as microhardness $[15,33,36]$ down to grain sizes of about $10 \mathrm{~nm}$. However, annealing at 250,400 , and $500^{\circ} \mathrm{C}$ results in a significant loss in elongation at fracture [7]. The position and slope of the HP straight line can be changed by adding iron $[15,23]$. Furthermore, the annealing time, e. g. for nc nickel above $220^{\circ} \mathrm{C}$, can have a considerable influence on the Vickers hardness measured [33]. Starting from an electrochemical deposition at $560 \mathrm{HV}$, after $220^{\circ} \mathrm{C}, 3 \mathrm{~h}$ increasing annealing time causes an initial increase in Vickers hardness to a maximum of $620 \mathrm{HV}$. Afterwards, the hardness decreases slowly and is still $415 \mathrm{HV}$ after $92 \mathrm{~h}$. In this case, the microstructure yields $75 \%$ larger grains of $700 \mathrm{~nm}$ surrounded by a fine nc microstructure. By comparison, the Vickers hardness determined for a uniform structure with a grain size of $700 \mathrm{~nm}$ is $200 \mathrm{HV}$ [33]. Impurities from saccharin used in electrochemical deposition [23, 33] have a decisive influence on this behavior of the nc nickel microstructure.

The above mentioned trends for the maximum hardness of nc metals depending on annealing temperature or annealing time are confirmed by current results and extensively evaluated literature data $[29,41]$. This shows that the "annealing hardening" observed increases with smaller grains, especially for grain sizes less than $10 \mathrm{~nm}$. Deviating from HP behavior or even more so from inverse HP behavior with softening, strength increase or an increase in hardness of more than $100 \%$ after annealing are determined for grain sizes below $5 \mathrm{~nm}$ [29]. Annealing hardening only occurs in nc metal alloys and in nc metals of low purity as an evaluation of 24 literature references reveals [41]. This is also obtained for nc nickel alloys and nc nickel with additives [7, 15, 33, 37, 38]. Studies of pure nc nickel, deposited without additives [23, 40, 41], do not reveal any strength increase through annealing.

The thermal stability of nc materials or rather of nc nickel and nc nickel alloys is essentially based on the grain boundary state. High grain boundary energy and 
grain boundary density of nc materials are decisive for grain growth [29, 38, 41-45]. Two elementary approaches in order to explain reduced grain growth are [42, 43, 44]: (i) The thermodynamic approach to reducing grain boundary energy as the driving force for grain growth is marked by the deposition of alloy or impurity atoms at the grain boundaries and by decreasing the dislocation density in the grain boundary region with a specific heat treatment. (ii) The kinetic approach assumes the anchoring of the grain boundaries and thus the reduction of grain boundary mobility. This is also done by adding alloy or foreign atoms such as sulphur [29, 39, 41-45] or by second phases [38, 39, 43]. The product of grain boundary energy (i) and grain boundary mobility (ii) is considered to be decisive for thermal stability and grain boundary stability, respectively [29, 43].

The grain boundary stability of nc metals is of considerable importance for plastic deformation, hardness and strength at room temperature [29]. Grain boundaries of low stability in high-purity nc metals without grain boundary precipitation plastify above a critical grain size by dislocation sliding according to Hall-Petch behavior. Below the critical grain size, grain boundary sliding and grain rotation occur followed by a decrease in strength. Nc metals with stable grain boundaries can be generated by specific annealing with a relaxation and segregation of dissolved atoms at the grain boundaries. They show grain boundary precipitation and low dislocation densities at the grain boundaries together with a decrease in microstrains or residual stress in the grain boundary region at a decrease in grain boundary energy and volume [29, 41, 45]. Grain boundary sliding is suppressed and consequently partial dislocations at the grain boundaries take on plastic deformation. Therefore, extremely small grains $(<10 \mathrm{~nm})$ require very high load induced stress to initiate dislocation movement. Thus, annealing hardening can cause considerable increases in hardness and strength [29, 41].

Our basic investigations deal with nc nickel-iron alloys, which are electrochemically deposited as layers with direct current and subsequently annealed in a vacuum furnace at various temperatures. XRD and TEM analyses, microbending and instrumented indentation hardness tests are carried out before and after annealing to characterize the microstructure and the mechanical properties. The results provide detailed information on the thermal stabil- ity of the investigated nickel-iron alloys. The effects of heat treatment on the microstructural parameters and the associated change in mechanical properties are discussed. Users are provided with temperature limits available for component postprocessing and short-term higher temperature use. However, the mechanical material properties determined only apply to material conditions after the respective annealing treatment at ambient conditions, i. e. at room temperature. For an application of the material properties for LIGA micro-components for MEMS it is necessary to consider the manufacturing parameters, the microstructure and geometric conditions.

\section{Experimental procedure}

The nickel-iron layers are electrodeposited on $100 \mathrm{~mm}$ copper discs provided by a manufacturer of microdrives. An industrial electrolyte $(\mathrm{pH}=3)$ especially developed for microsystem technology is used for the electrochemical deposition [3]. Efforts are made to generate highly uniform microstructures on larger surface areas. The direct current (DC) density is varied from 0.5 to $5 \mathrm{~A} \times \mathrm{dm}^{-2}[3,10]$. The iron content of the finished nickel-iron layers measured by EDX is 5.7 to 17.7 wt.-\% Fe (see Table 1). To take $5 \times 5 \mathrm{~mm}^{2}$ square specimens and strips, respectively, microbending specimens from the deposited layers, a precision cutting machine is used. In the following, the small bending specimens are referred to as "microbending specimens".

To manufacture microbending specimens (see Table 1) from the layer/coating strips, the layer strips are attached to a specimen carrier using hot glue at $120^{\circ} \mathrm{C}$ for $5 \mathrm{~min}$ [3]. After the surface grinding of the copper and nickel-iron faces, the layer strips are further machined to a thickness of $0.3 \mathrm{~mm}$ by using finish grinding and polishing equipment. This results in a specimen surface finish without grooves with a low roughness value $\mathrm{R}_{\mathrm{a}}<0.1 \mu \mathrm{m}$. $\mathrm{An}_{\mathrm{Al}_{2} \mathrm{O}_{3}}$ cutting disc is used to separate the microbending specimens. Then, the microbending specimens are detached from the specimen carrier by heating $\left(120^{\circ} \mathrm{C}\right.$ for $\left.5 \mathrm{~min}\right)$ and melting the hot glue. Figures $1 \mathrm{a}$ and $1 \mathrm{~b}$ show the geometry of the microbending specimens and a finished microbending specimen. In the next step, a part of the DC-plated microbending specimens were heated at a heating rate of $5 \mathrm{~K} \times \mathrm{min}^{-1}$ and annealed for $2 \mathrm{~h}$ in a vacuum furnace ( $\left.\mathrm{p}<10^{-5} \mathrm{mbar}\right)$ at 200, 220, 240, 260, 280, 300,400 or $800{ }^{\circ} \mathrm{C}$ and then slowly cooled down to room temperature at a cooling rate of $1 \mathrm{~K} \times \mathrm{min}^{-1}$.

To manufacture the $5 \times 5 \mathrm{~mm}^{2}$ square specimens (see Table 1), after cutting and attaching on a specimen carrier, the copper substrate is removed by grinding. Then, heat treatment is applied for $2 \mathrm{~h}$ at 200 , $220,240,260,280,300,400$ or $800{ }^{\circ} \mathrm{C}$ as for the microbending specimens. After slow furnace cooling (see microbending specimens), the specimens are embedded in warm embedding material $\left(150^{\circ} \mathrm{C}\right.$ for $10 \mathrm{~min})$. Finish grinding and polishing completes the preparation (see above).

The characterizing of the available $\mathrm{nc}$ microstructures is performed by means of X-ray diffraction (XRD). Here, a $\psi$-diffractometer (manufactured by the company: GE Sensing \& Inspection Technologies $\mathrm{GmbH}$, type: $\mathrm{XRD} 3003 \mathrm{PTS} \mu \mathrm{B}$ ) is used on the specimens' surfaces using a $\mathrm{Cu}$ K $\alpha$-beam and a $0.2 \mathrm{~mm}$ diameter primary beam at the center of the diffractometer.

To determine grain sizes and microstrains, respectively, lattice strains by means of the modified Williamson-Hall plot measured at $\{311\},\{222\}$ and $\{400\}$ inter-

\begin{tabular}{|c|c|c|c|c|}
\hline $\begin{array}{c}\text { Disc number or } \\
\text { specimen series }\end{array}$ & $\begin{array}{c}\text { Current density } \\
\left(\mathrm{A} \times \mathrm{dm}^{-2}\right)\end{array}$ & $\begin{array}{c}\text { Iron content } \\
(\text { wt.-\%) }\end{array}$ & Microbending specimen & $\begin{array}{c}\text { Square specimen } \\
\left(5 \times 5 \mathrm{~mm}^{2}\right)\end{array}$ \\
\hline R001-DC-0-5 & 5.0 & 5.7 & $\times$ & $\times$ \\
\hline R006-DC-0-3 & 3.0 & 8.8 & & $\times$ \\
\hline R005-DC-0-1.5 & 1.5 & 13.4 & $\times$ & \\
\hline R007-DC-0-0.5 & 0.5 & 17.7 & $\times$ & $\times$ \\
\hline
\end{tabular}

Table 1: Manufacturing parameter current density of electrochemical DC deposition, received iron content, and specimen type a)

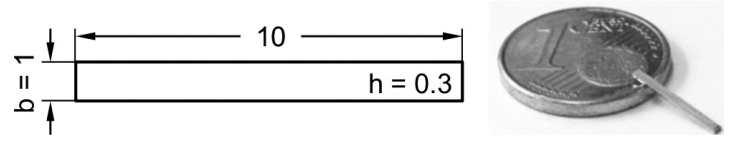

b)

Figure 1: a) Geometry of microbending specimens, b) microbending specimen manufactured by electrochemical deposition, grinding, and polishing 


\begin{tabular}{|c|c|c|c|}
\hline \multirow{2}{*}{$\begin{array}{c}\text { Deposited } \\
\text { specimen }\end{array}$} & XRD & TEM & SEM \\
\cline { 2 - 4 } & \multicolumn{4}{|c|}{ Grain size $(\mathrm{nm})$} \\
\hline DC-0-3-RT & 11 & 8 & - \\
\hline PR-200-1-RT & 17 & 11 & - \\
\hline DC-0-5-400 & 148 & - & 411 \\
\hline
\end{tabular}

Table 2: Grain sizes to various determination methods of DC-plated specimens and of pulsereverse plated $(P R)$ specimen without annealing $(R T)$, and after annealing $\left(400^{\circ} \mathrm{C}\right)$

ference line widths are used [46, 47]. Interferences (\{111\}, \{200\}, \{220\}) overlapping with other phases, are excluded from evaluation. To verify the grain sizes determined by XRD, the results in Table 2 are compared with results of TEM and scanning electron microscope (SEM) images. The grain sizes determined using both methods XRD and TEM are in good accordance with those specimens deposited using directcurrent and a current density of $3 \mathrm{~A} \times \mathrm{dm}^{-2}$ (DC-0-3-RT) as well as those deposited using pulse-reverse current at $200 \mathrm{~Hz}$ and a current density of $1 \mathrm{~A} \times \mathrm{dm}^{-2}$ (PR-200-1-RT). The specimen annealed at $400{ }^{\circ} \mathrm{C}$ (DC-0-5400) shows a grain size of $148 \mathrm{~nm}$ from the XRD measurement and a grain size of $411 \mathrm{~nm}$ in an SEM image due to the presence of annealing subgrain boundaries, being detectable with XRD measurements but not in SEM images of nanomaterials [48]. This leads to different results by using the two methods.

It is not possible to determine the grain size of specimens annealed at $800{ }^{\circ} \mathrm{C}$ by $\mathrm{XRD}$, because microcrystalline $(\mathrm{mc})$ grains are too coarse for applying this method [49]. A light microscope and the linear intercept method according to DIN EN ISO 643 are used to determine these coarser mc grain sizes. For this, the microstructure is etched beforehand with Nim3 etchant [50].

XRD texture analyses, possessing rotationally symmetric pole figures in all cases, can be evaluated by the relatively simple Harris-Texture Index

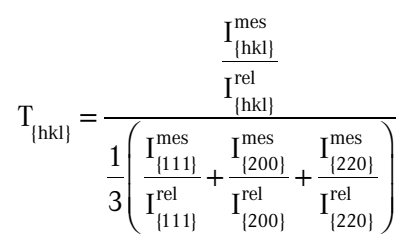

for the tilt angle $\psi=0^{\circ}$ [51]. The lattice planes $\{111\},\{200\}$ and $\{220\}$ were investigated. $\mathrm{I}_{\{\mathrm{hkl}\}}^{\mathrm{mes}}$ and $\mathrm{I}_{\{\mathrm{hkl}\}}^{\mathrm{rel}}$ are the measured and relative [52] intensities of interference from NiFe specimens. If an anisotropic microstructure is present, $\mathrm{T}_{\{\mathrm{hkl \}}}$ assumes a value greater than 1 , and even up to a maximum of 3 for a strongly pronounced texture. For isotropic microstructures, $\mathrm{T}_{\{111\}}=1, \mathrm{~T}_{\{200\}}=1$, and $\mathrm{T}_{\{220\}}=1$.

Moreover, a scanning electron microscope (SEM) (by Zeiss, type: SUPRA 40) equipped with EDX (by Bruker, type: QUANTAX 5010) is used for microstructural and element analyses.

In addition to this, it is possible to render the nc microstructures visible through transmission electron microscopy (TEM by Joel, type: JM2010) and to compare the nano-grain sizes with those determined by the XRD measurements.

For the instrumented indentation testing the same specimens are used as for the previous XRD analyses. An instrumented indentation-hardness tester (type Fischerscope $^{\mathrm{TM}}$ ), having a diamond pyramid indenter, is used to carry out the micro-hardness testing according to Vickers. The testing load of $98.1 \mathrm{mN}$ is applied for $20 \mathrm{~s}$, held for $10 \mathrm{~s}$ and unloaded in $20 \mathrm{~s}$. From the recorded load-indentation curves indentation hardness and the indentation modulus are evaluated according to DIN EN ISO 14577. The indentation hardness is measured using the $5 \times 5 \mathrm{~mm}^{2}$ square specimens from the same discs as those of the microbending specimens. To achieve average values for the indentation modulus and the indentation hardness, a $3 \times 3$ measuring point matrix with a dimension of $100 \times 100 \mu \mathrm{m}^{2}$ is placed at the middle of the specimens.

Microbending tests with plain specimen geometry (see Figure 1) are used to determine characterizing parameters for quasistatic material behavior. The parameters are $0.01-\%$ offset yield strength $\mathrm{R}_{\mathrm{p} 0.01}{ }^{*}$, bending strength $\mathrm{R}_{\mathrm{m}}{ }^{*}$, Young's modulus $\mathrm{E}$ and fracture strain on edge $\varepsilon_{\mathrm{E}, \mathrm{r}}$.

To determine these parameters a microtensile testing machine (by Messphysik, type: $\mu$ Strain) is used. For the microbending tests an accurate three-point bending tool was designed. The distance between the lower bearings of the 3-point bending tool is $1=4 \mathrm{~mm}$ with a central upper bearing for load application. All bearings, i. e. the two lower and the upper bearings, have a cylindrical geometry, each with $0.5 \mathrm{~mm}$ bearing radius. The bearings are rigidly mounted in press fits without any mobility in the tool. Microbending specimens are always freely placed on the lower bearings. The bearing distances, the bearings in height, the parallelism and flatness of the bearings are quite accurate in the $\mu \mathrm{m}$ range. To carry out the measurement, a force load cell up to $0.5 \mathrm{~N}$ and a laser speckle extensometer (LSE) with a resolution of $20 \mathrm{~nm}$ for measuring the maximum deflection are available. Verifying the LSE measurements with steel specimens are well in agreement with the results using strain gauges and have suitable values for the Young's modulus. All microbending tests are carried out using a constant edge strain rate $\dot{\varepsilon}_{\mathrm{E}}=10^{-3} \mathrm{~s}^{-1}$.

Before the evaluation of material parameters, it is necessary to determine the bending hardening curve from the forcedeflection curve (F-f curve). For this the edge stress in elastic loading

$\sigma_{E}=\frac{M_{b}}{W_{b}}$

and the fictitious edge stress in elasticplastic loading

$\sigma_{\mathrm{E}^{*}}=\frac{\mathrm{M}_{\mathrm{b}}}{\mathrm{W}_{\mathrm{b}}}>\mathrm{R}_{\mathrm{eS}}$

are calculated from the bending moment

$M_{b}=\frac{F 1}{4}$

and section modulus

$\mathrm{W}_{\mathrm{b}}=\frac{\mathrm{bh^{2 }}}{6}$.

Furthermore, the edge strain is determined from the measured deflection $\mathrm{f}$ [53]

$\varepsilon_{\mathrm{E}}=\frac{6 \mathrm{f} \mathrm{h}}{\mathrm{I}^{2}}$

Thus, the Young's modulus from the linear gradient

$\mathrm{E}=\frac{\sigma_{\mathrm{E}}}{\varepsilon_{\mathrm{E}}}$

and the $0.01-\%$ offset bending yield strength $\mathrm{R}_{\mathrm{p} 0.01}$ * as material resistance against exceeding a remaining edge strain of $\varepsilon_{\mathrm{E}}=0.01 \%$ can be determined from the bending hardening curve [53].

\section{Results}

The microstructure analyses by XRD and EDX in a DC-plated condition (without annealing) exhibit with a current density decreasing from $5 \mathrm{~A} \times \mathrm{dm}^{-2}$ to $0.5 \mathrm{~A} \times \mathrm{dm}^{-2}$ an increasing iron content (see Table 1) and also increasing microstrain, 0.36 to $0.65 \%$ for the $5 \times 5 \mathrm{~mm}^{2}$ square specimens (see Figure 2a) and 0.35 to $0.54 \%$ for the microbending specimens (see Figure 2b), respectively [3]. 
Starting from room temperature, the microstrains and grain sizes measured by XRD after annealing at low temperatures show practically no changes on an initial plateau. Conservatively considered, the structural variations start at the last point of the plateau before the observed variations (see Figures 2 and 3).

Figure 2 depicts the relationship between microstrain determined by XRD and the annealing temperature. Here, a reduction of the microstrain is initiated at rather low and somewhat different temperatures. The beginning of recovery involves a shift to higher temperatures, from 200 to 220 to $240{ }^{\circ} \mathrm{C}$, for $5 \times 5 \mathrm{~mm}^{2}$ square specimens with iron content increasing from 5.7 (R001-DC-0-5) to 8.8 (R006-DC-0-3) to $17.7 \mathrm{wt} . \%$ (R007DC-0-0.5) as shown in Figure 2a. For the microbending specimens, the beginning of recovery is measured at the same temperature of $200{ }^{\circ} \mathrm{C}$ for all iron contents 5.7 (R001-DC-0-5), 13.5 (R005-DC-0-1.5) and 17.7 wt. $\%$ (R007-DC-0-0.5) (see Figure $2 \mathrm{~b}$ ). Up to an annealing temperature of $280^{\circ} \mathrm{C}$, microstrains are almost completely eliminated for all specimens. The microstrains for $800{ }^{\circ} \mathrm{C}$ annealed specimens cannot be determined by X-rays due to the coarse grain sizes.

The grain sizes, after electrochemical deposition and before annealing, determined by XRD, are about $10 \mathrm{~nm}$ for all specimens with slightly higher values for the lower iron content (see Figure 3). Grain growth occurs at very low annealing temperatures for all four nickel-iron layers (R001-DC-0-5, R005-DC-0-1.5, R006-DC-0-3, and R007-DC-0-0.5), however at slightly higher temperatures than the decrease in microstrains (compare Figures 2 and 3). With increasing iron content, the temperatures at which grain growth begins are shifted to higher values from 220 to 240 to $260{ }^{\circ} \mathrm{C}$ for $5 \times 5 \mathrm{~mm}^{2}$ square specimens and from 240 to $260{ }^{\circ} \mathrm{C}$ for microbending specimens, respectively. After annealing at $400{ }^{\circ} \mathrm{C}$, the grain sizes obtained increase to $50 \mathrm{~nm}$ at $17.7 \mathrm{wt} . \%$ Fe to about $250 \mathrm{~nm}$ at 5.7 wt.- $\%$ Fe for the $5 \times 5 \mathrm{~mm}^{2}$ square specimens (see Figure 3a) and to $80 \mathrm{~nm}$ at 17.7 wt. $\%$ Fe to about $760 \mathrm{~nm}$ at 5.7 wt. $\%$ Fe for the microbending specimens (see Figure $3 b)$. With a further increase in the annealing temperature to $800{ }^{\circ} \mathrm{C}$, light microscopic images show very large grains with 19 to $74 \mu \mathrm{m}$ for both specimen types (see Figures $3 \mathrm{a}$ and $3 \mathrm{~b})$. The smaller grain size again occurs in the nickel-iron layers with the highest iron content. Additional precipi- tates are present within the microstructures of the specimens annealed at $800{ }^{\circ} \mathrm{C}$.

If the Harris-Texture index is considered as a function of the annealing temperature, a $\{111\}$ texture (Harris-Texture Index $\left.\mathrm{T}_{\{111\}}=1.5\right)$ and a rather weak $\{200\}$ texture $\left(\mathrm{T}_{\{200\}}=1.1\right)$ are recognizable after electrochemical deposition. After annealing at $200{ }^{\circ} \mathrm{C}$, the $\{111\}$ texture decreases slightly to $\mathrm{T}_{\{111\}}=1.4$ and the $\{200\}$ texture increases slightly to $T_{\{200\}}=1.2$. From an annealing temperature of $280^{\circ} \mathrm{C}$ up to an annealing temperature of $500^{\circ} \mathrm{C}$, a slight larger proportion of the $\{200\}$ lattice plane is determined parallel and rotationally symmetrical to the electrochemical deposition plane with $\mathrm{T}_{\{200\}}=1.4$ than with the $\{111\}$ plane $\mathrm{T}_{\{111\}}=1.3$ [47]. XRD analyses subsequent to annealing above $500{ }^{\circ} \mathrm{C}$ are not possible due to the larger grains.

The indentation modulus-temperature relationship is plotted in Figure 4a for the nickel-iron layers with the different iron contents. The DC-plated specimens have

a)

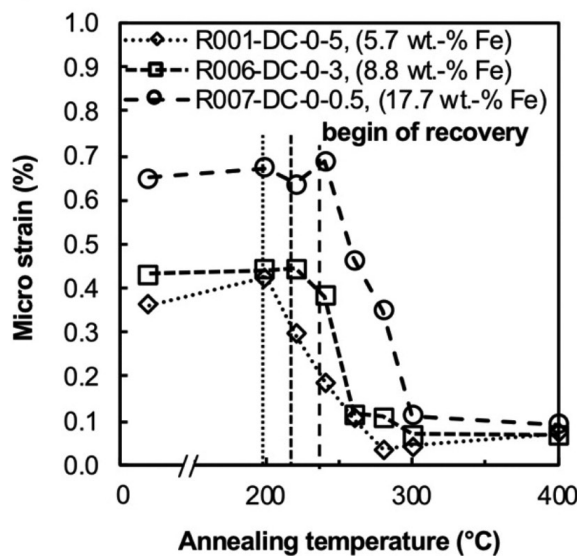

b)

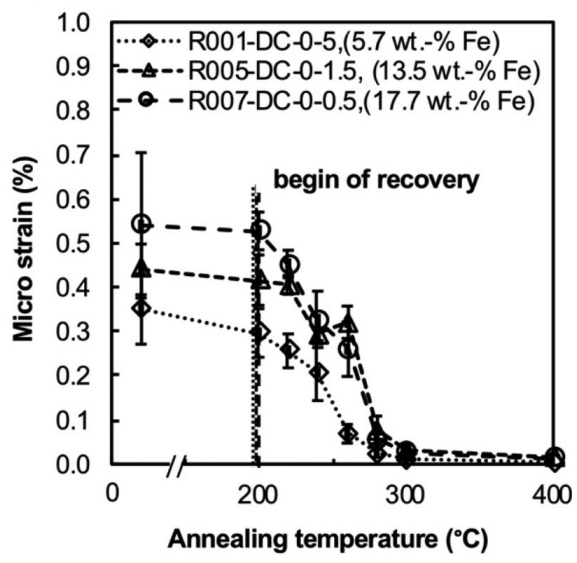

Figure 2: Microstrain $\eta$ of annealed nickel-iron layers as a function of annealing temperature $T_{a}$ of a) $5 \times 5 \mathrm{~mm}^{2}$ square specimens, b) microbending specimens a)

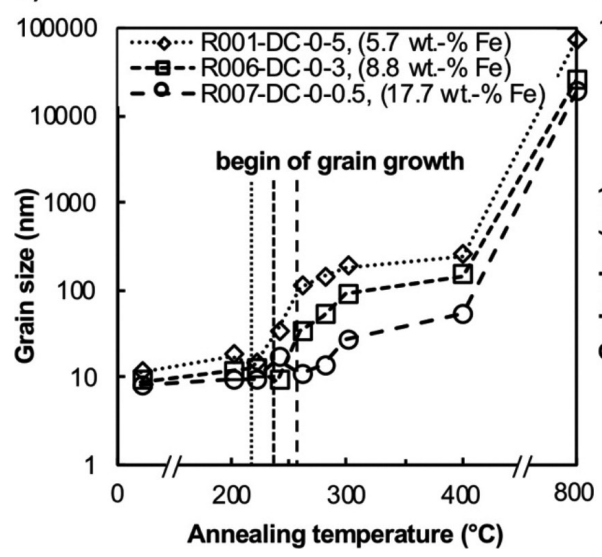

almost the same indentation moduli as for the DC-plated and specimens annealed at $200{ }^{\circ} \mathrm{C}$. Here, the increasing iron content reduces the indentation modulus slightly from 210 to 203 and finally to $195 \mathrm{GPa}$. In the nickel-iron layers R001-DC-0-5 and R006-DC-0-3 with 5.7 and 8.8 wt.-\% Fe, respectively, the indentation modulus increases significantly to about $260 \mathrm{GPa}$ with increasing annealing temperatures from 200 to $300{ }^{\circ} \mathrm{C}$. This level is maintained for the specimens annealed at $400{ }^{\circ} \mathrm{C}$. For the nickel-iron layer R007-DC-0-0.5 with 17.7 wt. $\% \mathrm{Fe}$, the indentation modulus increases above the specimens annealed at $220^{\circ} \mathrm{C}$. The lower maximum plateau of about $235 \mathrm{GPa}$ is also measured after annealing at 300 and $400{ }^{\circ} \mathrm{C}$. After annealing at $800{ }^{\circ} \mathrm{C}$ all measured values decrease. At specimens with the lowest 5.7 and the highest $17.7 \mathrm{wt} . \%$ iron content, the decrease to about $150 \mathrm{GPa}$ is significant, even far below the value of electrochemical deposition. By contrast, a decrease in the in-
Figure 3: Grain size D of annealed nickel-iron layers as a function of annealing temperature $T_{a}$ of a) $5 \times 5 \mathrm{~mm}^{2}$ square specimens, b) microbending specimens 
dentation modulus for the iron content 8.8 wt.- $\%$ to $240 \mathrm{GPa}$ is rather small.

All nickel-iron layers investigated show similar indentation hardness-temperature relationships as in Figure 4b. Already after an annealing treatment at $200{ }^{\circ} \mathrm{C}$, an increase in the indentation hardness is registered. If the maximum hardness is passed, the indentation hardness decreases and reaches, after annealing at $800{ }^{\circ} \mathrm{C}$, only 2,900 to $3,100 \mathrm{~N} \times \mathrm{mm}^{-2}$. That is about $40 \%$ of the DC-plated initial value. The maximum hardness values of the nickel-iron layers increase with increased iron content and occur at different temperatures. After annealing at $280{ }^{\circ} \mathrm{C}$, the highest hardness

a)

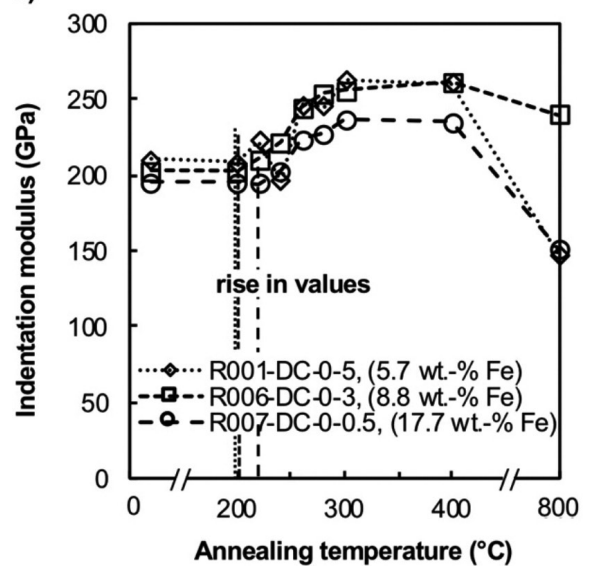

b)

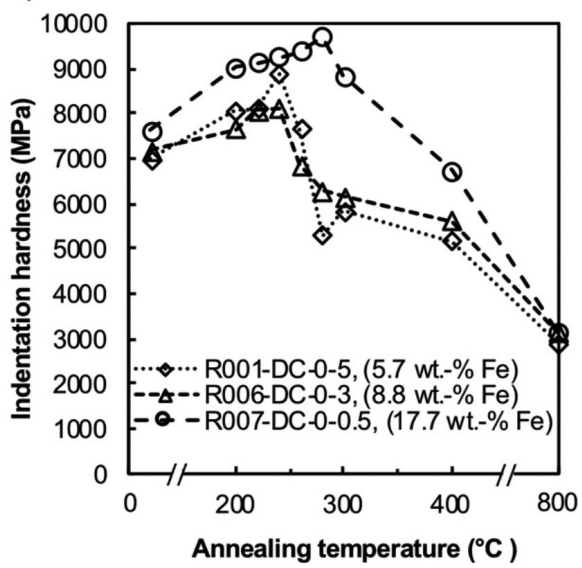

Figure 4: a) Indentation modulus $E_{I T}$, b) indentation hardness $H_{I T}$ as a function of annealing temperature $T_{a}$ of $5 \times 5 \mathrm{~mm}^{2}$ square specimens of annealed nickel-iron layers

a)

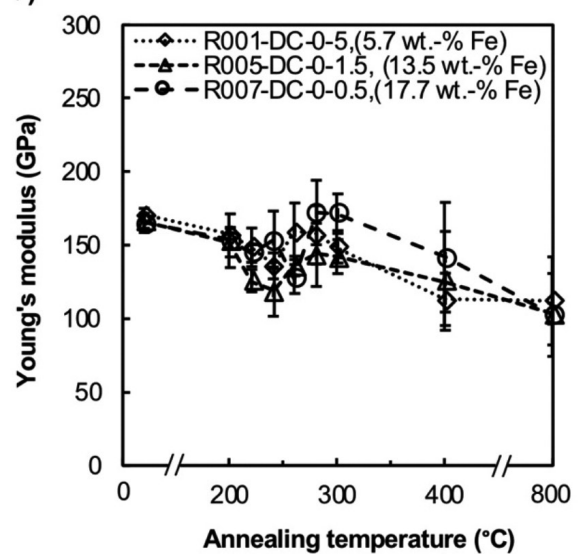

c)

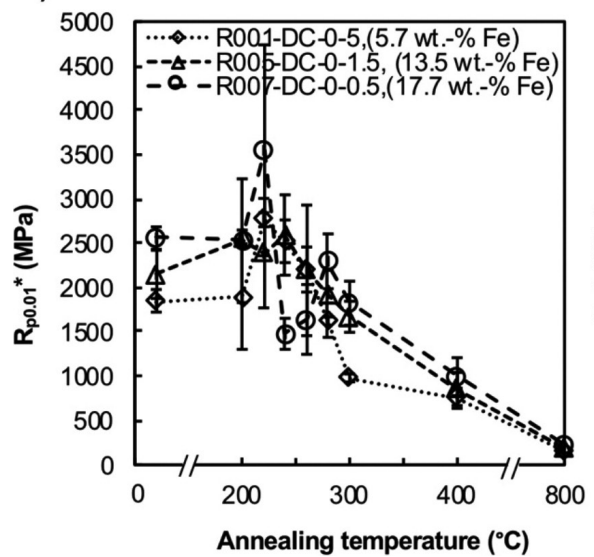

b)

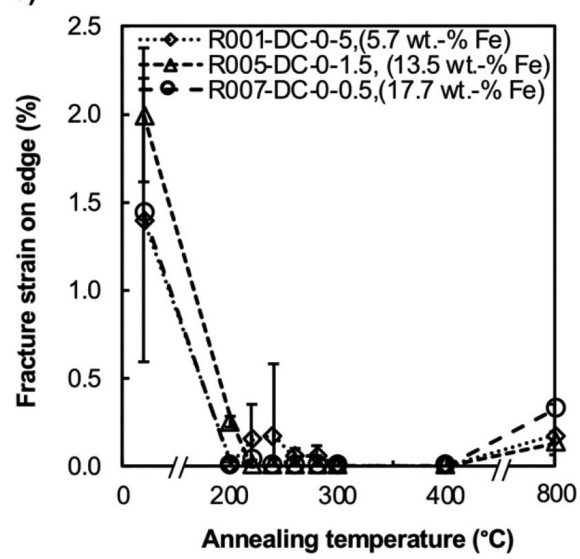

d)

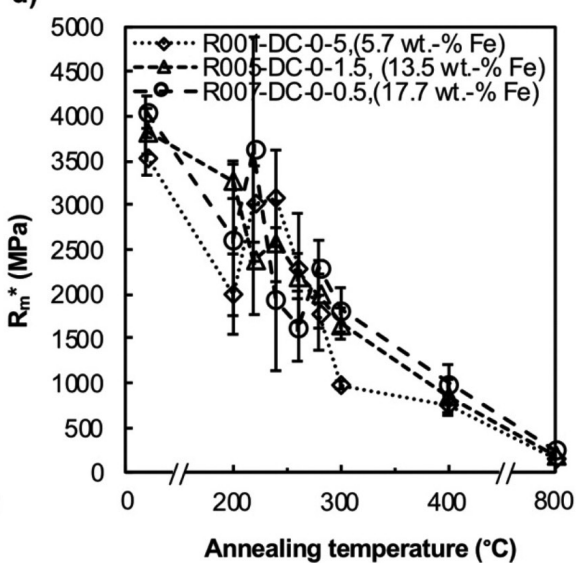

Figure 5: a) Young's modulus $E, b)$ fracture strain on edge $\left.\varepsilon_{E, r}, c\right)$ 0.01-\% offset bending yield strength $R_{p 0.01}{ }^{*}$, d) Bending strength $R_{m}{ }^{*}$ as a function of annealing temperature $T_{a}$ of microbending specimens of annealed nickel-iron layers

value $\left(9,705 \mathrm{~N} \times \mathrm{mm}^{-2}\right)$ is measured at the nickel-iron layer R007-DC-0-0.5 with the highest iron content of 17.7 wt.-\%. For the nickel-iron layers R001-DC-0-5 and R006DC-0-3 with lower iron contents of 5.7 and 8.8 wt.-\%, a maximum hardness with 8,882 and $8,111 \mathrm{~N} \times \mathrm{mm}^{-2}$ is obtained after annealing at $240{ }^{\circ} \mathrm{C}$.

The results of the microbending tests on the annealed specimens are given in the following. It should be noted that due to a certain deformation as a result of the annealing process, the microbending specimens do not always lie exactly on the bearings of the bending tool. This leads to a more pronounced scatter of the results in the DCplated and annealed state as compared to the as-received DC-plated specimens (see Figure 5). The results presented are mean values from each three bending tests.

The Young's moduli measured at room temperature after annealing at different temperatures are shown in Figure 5a for the nickel-iron layers R001-DC-0-5, R005DC-0-1.5 and R007-DC-0-0.5 with the iron contents 5.7, 13.5 and 17.7 wt.-\%. For all nickel-iron layers investigated, similar curves result. For specimens of DC-plated layers, without annealing, the Young's modulus ranges from 165 to $170 \mathrm{GPa}$. After annealing at $200{ }^{\circ} \mathrm{C}$, Young's modulus decreases and reaches a minimum after 240 (R001-DC-0-5 and R005-DC-0-1.5) or $260{ }^{\circ} \mathrm{C}$ (R007-DC-0-0.5), respectively, and then reaches a maximum value after annealing at 260 (R001-DC-0-5) or $280{ }^{\circ} \mathrm{C}$ (R005-DC-0-1.5 and R007-DC-0-0.5), respectively. The Young's modulus drops down to 103 to $112 \mathrm{GPa}$ for even higher annealing temperatures of $800^{\circ} \mathrm{C}$. Specimens with the highest iron content (R007DC-0-0.5) usually show the highest Young's moduli determined at various annealing temperatures.

With respect to the $0.01 \%$ offset bending yield strength $\mathrm{R}_{\mathrm{p} 0.01}{ }^{*}$, the nickel-iron layers treated at low annealing temperatures between 220 (R001-DC-0-5 and R007-DC-0-0.5) and $240{ }^{\circ} \mathrm{C}$ (R005-DC-0-1.5) show an increase of $\mathrm{R}_{\mathrm{p} 0.01}{ }^{*}$ above non-heat treated specimens for room temperature (see Figure 5c). The maximum increase results for the nickel-iron layer (R007-DC-0-0.5) with the largest iron content $17.7 \mathrm{wt} .-\%$ from 2,558 $\mathrm{MPa}$ at room temperature (without annealing) to $3,548 \mathrm{MPa}$ after a $220^{\circ} \mathrm{C}$ annealing treatment. After annealing at still higher temperatures, the $0.01-\%$ offset bending yield strength $\mathrm{R}_{\mathrm{p} 0.01}{ }^{*}$ drops sharply and only reaches values between 152 and $227 \mathrm{MPa}$ after annealing at $800{ }^{\circ} \mathrm{C}$. 
Extremely high bending strengths $\mathrm{R}_{\mathrm{m}}$ * of 3,547 (R001-DC-0-5), 3,830 (R005DC-0-1.5) to $4,044 \mathrm{MPa}$ (R007-DC-0-0,5) are determined at room temperature with increasing iron content 5.7, 13.5 to 17.7 wt.-\% (see Figure 5d). After annealing at $200{ }^{\circ} \mathrm{C}$, all determined bending strengths drop to a local minimum and reach a local maximum after annealing at 220 (R007DC-0-0.5) or $240{ }^{\circ} \mathrm{C}$ (R001-DC-0-5 and R005-DC-0-1.5), respectively. Further, the $\mathrm{R}_{\mathrm{m}}{ }^{*}$ values decrease and after annealing at $800{ }^{\circ} \mathrm{C}$ reach minima of 152 to $243 \mathrm{MPa}$. In the annealing temperature range 200 to $300{ }^{\circ} \mathrm{C}$, the strength values scatter considerably and make it difficult to distinguish between the individual nickel-iron layers.

Regarding ductility, the fracture strain after the annealing treatments for the selected annealing temperatures is shown in Figure 5b. After annealing at the lowest selected temperature, a significant reduction in fracture strain to values between 0 and $0.25 \%$ can be observed for all investigated nickel-iron layers. Up to annealing temperatures of 300 and $400{ }^{\circ} \mathrm{C}$ all fracture strains are about $0 \%$. After annealing at $800^{\circ} \mathrm{C}$, the fracture strain increases slightly from 0.1 to $0.3 \%$.

\section{Discussion}

The microstructure of the nickel-iron layers and their thermal stability is investigated through XRD. Bimodal structures are not detectable. Both investigated specimen types, the square specimens $5 \times 5 \mathrm{~mm}^{2}$ and the microbending specimens, show comparable results for the microstrains and grain sizes taking into account the existing scatter (see Figures 2 and 3). It should also be noted, that the XRD results for the $5 \times 5 \mathrm{~mm}^{2}$ square specimens are single measured values (see Figures $2 a$ and $3 a$ ), while for the microbending specimens the mean values and standard deviations each from three measurements (see Figures $2 b$ and $3 b$ ) are displayed. In Figure 3b, however, standard deviations of the grain sizes are not visible, caused by too small values. Both specimen types are taken from the same nickel-iron layers. However, the slight differences between the results of the two types of the specimens might depend on the specimen geometry, the preparation procedure and the position of the extracted specimens within the disc. From this it can be concluded that both specien types have approx. the same microstructural states.

Recovery begins slightly before primary recrystallization with a decline in micro- strains. The measured values of the nickeliron layers studied for the beginning of recovery at 200, 220 and $240{ }^{\circ} \mathrm{C}$ (see $5 \times 5 \mathrm{~mm}^{2}$ square specimens, Figure 2a) and $3 \times 200{ }^{\circ} \mathrm{C}$ (see microbending specimens, Figure $2 b$ ) and for the beginning of recrystallization at 220,240 and $260{ }^{\circ} \mathrm{C}$ (see Figure 3a) and 240, 260 and $260{ }^{\circ} \mathrm{C}$ (see Figure 3b) are almost the same for the $5 \times 5 \mathrm{~mm}^{2}$ square specimens and the microbending specimens. An increased iron content from 5.7 to 17.7 wt.- $\%$ has a slightly stronger microstructure stabilizing effect and thus permits a little higher annealing temperature without significant microstructural changes. The temperatures obtained for the start of recovery and recrystallization are comparable to those in the literature for similar iron contents $[7,41,45]$. Recovery is nearly completed at $280{ }^{\circ} \mathrm{C}$ (see Figure 2). Primary recrystallization at an annealing temperature of $300{ }^{\circ} \mathrm{C}$ leads to grain sizes of 27,89 , $184 \mathrm{~nm}$ for $5 \times 5 \mathrm{~mm}^{2}$ square specimens or $61,115,629 \mathrm{~nm}$ for microbending specimens, respectively. After annealing at $400{ }^{\circ} \mathrm{C}$, grain sizes of $54,148,252 \mathrm{~nm}$ for $5 \times 5 \mathrm{~mm}^{2}$ square specimens or 81,165 , $760 \mathrm{~nm}$ for microbending specimens are reached (see Figure 3). A completed secondary recrystallization at grain sizes of 19 to $74 \mu \mathrm{m}$ is observed in the specimens annealed at $800{ }^{\circ} \mathrm{C}$. The stabilizing effect of higher iron content explains the smaller grains at the particular annealing temperature (see Figure 3).

After annealing above the recrystallization temperature, in this case after secondary recrystallization at $800^{\circ} \mathrm{C}$, clear precipitates are visible in the light microscopic images of the microstructure. SEM investigations confirm the precipitations. EDX analyses show a sulfur content of 14 wt.-\% within the precipitates. Further SEM and EDX investigations on specimens annealed at $400{ }^{\circ} \mathrm{C}$ also confirm precipitates with higher sulfur contents located within the grains and partly at the grain boundaries, as has already been shown in $[10,47]$.

At low annealing temperatures below the corresponding recrystallization temperature, first atoms from the impurities (here small sulfur atoms) and then those from the alloys (here the larger iron atoms) segregate at the grain boundaries $[23,29,38-$ 45]. The segregated atoms are able to thermally stabilize the grain boundaries and thus also the nc microstructure. Grain boundary stabilization is caused by relaxation due to a reduction of microstrain and the segregation of solute atoms at grain boundaries. Thus, the grain boundary energy is reduced, and the migration of the grain boundaries is impeded. By a further increase of the annealing temperature, solute atoms within the grain boundaries initiate to form precipitates [43]. The precipitates at the grain boundaries grow, the microstructure becomes unstable and recrystallization begins. Coarser precipitates are inserted into the larger grains and only a few remain at the grain boundaries. However, the thermodynamic stabilization effect of diverse atoms at the grain boundaries varies. E. g. in nickel, iron has a lower thermally stabilizing effect than phosphorus, molybdenum, tungsten or yttrium, which also affects the mechanical properties [7, 23, 33, 38, 42 - 44].

The mechanical behavior investigated is influenced by various parameters. On the one hand, there are the parameters influencing the nickel-iron layers deposited and their microstructural changing during annealing. On the other hand, the two test methods, i.e. instrumented indentation and 3-point bending, differ. The influence on the microstructure comprises changes in the grain structure and in the grain boundaries, especially atomic segregations at the grain boundaries, which already form before recrystallization [43], changes of microstrains caused by reducing the defects in the microstructure, as well as during recrystallization, the variation in grain sizes and the formation of bimodal structures and texture change. Differences in test methods are the uniaxial and multiaxial stress state in the bending test and the indentation test, respectively. Moreover, larger material volumes are stressed during the bending test than during the indentation test. There are also differences in the load-time function in both tests. In the bending test, Young's modulus E is measured at the beginning of loading before the plastic deformation. During the indentation test, the indentation modulus $\mathrm{E}_{\mathrm{IT}}$ is measured after plastic deformation is initiated. Changes in microstructure and strength can be assumed as a result of plastic deformation during the indentation hardness measurement prior to the determination of the modulus with the indenter. In addition, the Bauschinger effect may have an influence on the measurement of the indentation modulus when relieving the indenter.

Indentation modulus $\mathrm{E}_{\mathrm{IT}}$ and Young's modulus $\mathrm{E}$ both show a clear trend with increasing annealing temperature (see Figure 6). The changes observed at certain 
temperatures are very similar for the nickel-iron layers investigated, in each case for the Young's modulus E (R001-DC-0-5, R005-DC-0-1.5, R007-DC-0-0.05) as well as for the indentation modulus $\mathrm{E}_{\mathrm{IT}}$ (R001DC-0-5, R006-DC-0-3, R007-DC-0-0.05). However, the indentation moduli are always higher than the Young's moduli. With respect to this difference the measuring effect has to be taken into account as described above.

Starting from room temperature, after electrochemical deposition, the mean values of $\mathrm{E}_{\mathrm{IT}}$ for the three investigated nickeliron layers are nearly constant at approx. $200 \mathrm{GPa}$ up to 200 and $220^{\circ} \mathrm{C}$, respectively (see Figure 6, R001-DC-0-5 (5.7 wt.-\% Fe) and R006-DC-0-3 (8.8 wt.-\% Fe) and R007DC-0-0.05 (17.7 wt.-\% Fe)). By contrast, the initial Young's modulus E $=168 \mathrm{GPa}$ in Figure 6 decreases moderately to $154 \mathrm{GPa}$ after the first annealing temperature of $200{ }^{\circ} \mathrm{C}$ (R001-DC-0-5, R005-DC-0-1.5 (13.5 wt.-\% Fe) and R007-DC-0-0.5). There is no change in the microstrain at $200{ }^{\circ} \mathrm{C}$ (see Figure 2) and no measurable variation in grain size (see Figure 3) so that a slight decrease in the Young's modulus is difficult to explain. However, it is possible that this small decrease in Young's modulus may be due to segregated smaller atoms at grain boundaries influencing the elastic behavior.

As recovery above 200 to $240{ }^{\circ} \mathrm{C}$ begins (see grey vertical, fine dotted or solid lines in Figure 6), both, $\mathrm{E}$ and $\mathrm{E}_{\mathrm{IT}}$ change significantly. From 200 or $240{ }^{\circ} \mathrm{C}$, the Young's modulus $\mathrm{E}$ is reduced to a minimum. By comparison, $\mathrm{E}_{\mathrm{IT}}$ shows increasing values up to about $300{ }^{\circ} \mathrm{C}$. Effects such as increased segregations (e.g., sulfur and iron) at the grain boundaries, especially at the onset of recrystallization, changes in grain size and texture, may overlap as the annealing temperature increases.

The bimodal microstructures and the test methods could offer a further explanation for changing elastic properties. Such microstructures occur after annealing at about $200{ }^{\circ} \mathrm{C}$ and above and are not detectable by XRD. Nevertheless, the nanocrystalline microstructure dominates as a matrix for annealing temperatures that are not too high [33, 37, 41]. Thus, in the bending test, larger material volumes are stressed than in the indentation test, affect the results for the entire loaded bimodal microstructure, for the nanocrystals and for the embedded larger crystals. By contrast, indentation measurements are only carried out locally, e.g. only in the nanocrystalline matrix.

At the beginning of primary recrystallization at 220 and $260{ }^{\circ} \mathrm{C}$ (see grey vertical, bold dotted and solid lines in Figure 6), increasing values of $\mathrm{E}$ and $\mathrm{E}_{\mathrm{IT}}$ occur. The increase of $\mathrm{E}_{\mathrm{TT}}$ to a plateau at 300 to $400{ }^{\circ} \mathrm{C}$ and of $\mathrm{E}$ to a maximum at 260 and $280^{\circ} \mathrm{C}$ after the minimum could be related to an increasing amount of segregations at the grain boundaries. Reinforcement by segregations can result in increased cohesion [40], and thus an increase of modules is possible. But this depends strongly on the atoms involved. If the Bauschinger effect is applied to the indentation test, its impact could decrease from 280 or $300{ }^{\circ} \mathrm{C}$, when microstrains become minimal (see Figure 2).

At the subsequent annealing temperatures starting at approx. $280^{\circ} \mathrm{C}, \mathrm{E}$ decreases again, while $\mathrm{E}_{\text {IT }}$ increases at $300^{\circ} \mathrm{C}$ and remains constant to up to $400{ }^{\circ} \mathrm{C}$ on a higher plateau. Growing grains, which at certain temperatures are no longer bimodal but uniform [32, 33], precipitations predominantly within the grains and altered textures do not lead to any further increase in $\mathrm{E}_{\mathrm{IT}}$ and decrease in E. Secondary recrystallization as a result of annealing at $800{ }^{\circ} \mathrm{C}$ causes a considerable decrease in the measured values $\mathrm{E}$ and $\mathrm{E}_{\mathrm{IT}}$, which are mostly below the respective initial values of the electrochemical deposition.

Especially the reduction of $\mathrm{E}$ to a minimum for the bending test could also be linked to a decreasing $\langle 111\rangle$ and an increasing of the $\langle 200\rangle$ texture. Nickel possesses a large elastic anisotropy and a large anisotropy factor whose smallest elastic modulus values are in the direction of $\langle 100\rangle$ and largest in the direction of <111> [54]. As a result of annealing, the proportion of the $<100>$ direction increases only slightly, but from about $280^{\circ} \mathrm{C}$ it has a greater proportion than the $\langle 111\rangle$ direction. Both directions agree in each case with the direction of the highest stress in the bending test. In the case of indentation hardness testing, on the other hand, this is different and is caused by multi-axial stress.

All nickel-iron layers with different iron contents investigated show a comparable relationship between $\mathrm{E}$ and the annealing temperature. The same applies to the indentation modulus $\mathrm{E}_{\mathrm{IT}}$.

Indentation hardness already increases considerably at the lowest annealing temperature chosen, which is to say, at $200{ }^{\circ} \mathrm{C}$ (see Figures $4 \mathrm{~b}$ and 7). This applies to all investigated nickel-iron alloys with iron contents 5.7, 8.8 and 17.7 wt.-\% (R001DC-0-5, R006-DC-0-3, R007-DC-0-0.5). The behavior is in contrast to the initially unchanged indentation modulus. This cannot be explained by the approx. constant XRD microstrain measurements and grain size determinations at $200{ }^{\circ} \mathrm{C}$ (see Figures 2 and 3). However, the literature agrees that an increase in hardness and strength occurs after low-temperature annealing at 200 to $250^{\circ} \mathrm{C}$ of electrochemically deposited nickel-iron with saccharin, although no or only a certain grain growth is observed $[7,15,41]$. Here, the annealing temperatures $240,240,280^{\circ} \mathrm{C}$ resulting in extremely high maximum hardness values $8,883,8,111,9,705 \mathrm{~N} \times \mathrm{mm}^{-2}$ are close to the beginning primary recrystallization temperatures 220, 240, $260^{\circ} \mathrm{C}$ (R001DC-0-5, R006-DC-0-3, R007-0-0.5) measured through XRD. The subsequent decrease in hardness can be explained by the
Figure 6: Young's modulus E and indentation modulus $E_{I T}$ VS. annealing temperature $T_{a}$ of microbending specimens, and of $5 \times 5 \mathrm{~mm}^{2}$ square specimens of DC-plated and annealed nickel-iron layers for a) R001-DC-0-5 with 5.7, b) R005-DC-0-1.5 with 13.5, and R006-DC-0-3 with 8.8, and c) R007-DC-0-0.5 with 17.7 wt. $\%$ iron (grey vertical lines show the beginning of recovery (fine lines), and beginning of grain growth (bold lines) measured through XRD) a)

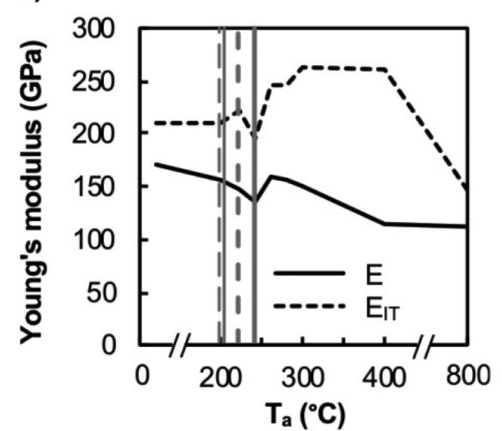

b)

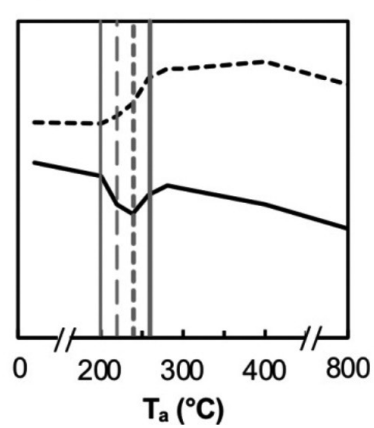

c)

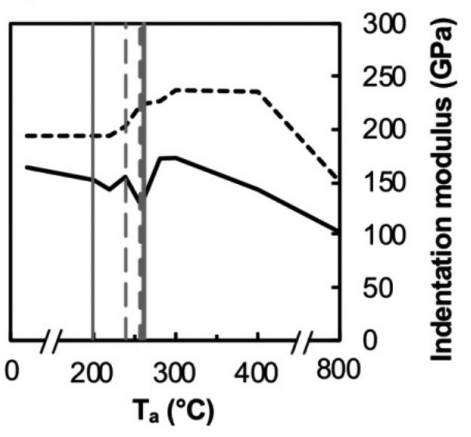


changing microstructure due to higher annealing temperatures. The hardness curves for both lower iron contents of 5.7 and 8.8 wt.-\% Fe exhibit similarly high hardness values (see Figure 4b). For a higher iron content of $17.7 \mathrm{wt} . \% \mathrm{Fe}$, by contrast, the hardness values overall are significantly larger. The increases in hardness after annealing at low temperatures are attributed to impurities and solutes in nc materials and the resulting segregations of atoms at the grain boundaries as well as to a relaxation of the grain boundaries $[7,15$, $29,41]$. For specimens with a higher iron content of 17.7 wt.-\%, a stronger increase in indentation hardness tends to be achieved (see Figures $4 b$ and 7). This could mean that annealing hardening is caused by the grain boundary segregation of sulfur but also of iron atoms. After secondary recrystallization at $800^{\circ} \mathrm{C}$, the hardness values of all nickel-iron layers drop below the respective initial values of electrochemical deposition to 2,883, 3,116, 3,107 $\mathrm{N} \times \mathrm{mm}^{-2}$.

For $\mathrm{R}_{\mathrm{p} 0.01}{ }^{*}$ no (R001-DC-0-5, R007DC-0-0.5) or a medium (R005-DC-0-1.5) change to the initial values at room temperature is determined after annealing at $200{ }^{\circ} \mathrm{C}$ (see Figures 5C and 8). Respective maximum $\mathrm{R}_{\mathrm{p} 0.01}$ * values 2,764, 2,593, 3,548 MPa can be observed at temperatures of $220,240,220^{\circ} \mathrm{C}$. That is after the beginning of recovery at $200{ }^{\circ} \mathrm{C}$ for all three ma- terials (see Figure 2b) and before the beginning of the respective primary recrystallization at $240,260,260{ }^{\circ} \mathrm{C}$ (see Figures $3 \mathrm{~b}$ and 8, R001-DC-0-5, R005-DC-0-1.5, R007DC-0-0.5 with 5.7, 13.4, 17.7 wt.-\% Fe). Measured microstrains are still relatively high at the maximum of $\mathrm{R}_{\mathrm{p} 0.01}{ }^{*}$ (see Figures $2 \mathrm{~b}$ and 8 ). This consequently means for $\mathrm{R}_{\mathrm{p} 0.01}{ }^{*}$ that low temperature annealing results in hardening without any change in the XRD measured grain size. Above the maximum values and slightly before the beginning of the primary recrystallization determined, $\mathrm{R}_{\mathrm{p} 0.01}{ }^{*}$ decreases. Above $300{ }^{\circ} \mathrm{C}$ and even above $400^{\circ} \mathrm{C}$, the drop is clearly below the initial value of electrochemical deposition. An intermediate minimum as well as an intermediate maximum is determined for the specimens with $17.7 \mathrm{wt} . \% \mathrm{Fe}$ after 240 and $280^{\circ} \mathrm{C}$, respectively. Secondary recrystallization at $800^{\circ} \mathrm{C}$ provides extremely low $\mathrm{R}_{\mathrm{p} 0.01}$ * values of 152,185 , $227 \mathrm{MPa}$ (see Figure 8). This may be caused by large grains and/or coarse precipitates.

The $\mathrm{R}_{\mathrm{m}}{ }^{*}$ of the three nickel-iron layers investigated decreases significantly after annealing at temperature of $200{ }^{\circ} \mathrm{C}$ and reaches values in the same range as $\mathrm{R}_{\mathrm{p} 0.01}{ }^{*}$ at 200 or $220^{\circ} \mathrm{C}$ (see Figure 8). $\mathrm{R}_{\mathrm{p} 0.01}{ }^{*}$ and $\mathrm{R}_{\mathrm{m}}{ }^{*}$ remain identical for the higher annealing temperatures with some small exceptions. Almost identical values of $\mathrm{R}_{\mathrm{m}}{ }^{*}$ and $\mathrm{R}_{\mathrm{p} 0.01}{ }^{*}$ could be explained by the fact that strain hardening by dislocations can hardly occur.
Fracture strain on edge $\varepsilon_{\mathrm{E}, \mathrm{r}}$ is already relatively low for the electrochemically deposited nickel-iron layers, namely 1.4, 2.0, $1.4 \%$, but decreases down to nearly $0 \%$ for all tested specimens after annealing at $200{ }^{\circ} \mathrm{C}$ (see Figure 8). Only in the exceptions in which $\mathrm{R}_{\mathrm{p} 0.01}{ }^{*}$ and $\mathrm{R}_{\mathrm{m}}{ }^{*}$ are somewhat different do the values of $\varepsilon_{\mathrm{E}, \mathrm{r}}$ slightly deviate from $0 \%$. After secondary recrystallization at $800{ }^{\circ} \mathrm{C}$, the $\varepsilon_{\mathrm{E}, \mathrm{r}}$ values for the three nickel-iron layers increase slightly from $0 \%$ at $400{ }^{\circ} \mathrm{C}$ to $0.17,0.13,0.32 \%$.

Overall, indentation hardness measurements and bending tests show the maximum hardening of the nickel-iron layers at low annealing temperatures of 240, 240, $280{ }^{\circ} \mathrm{C}$ (see Figure 7) and of 220, 240, $220^{\circ} \mathrm{C}$ (see Figure 8). These temperatures are in the range of the beginning primary recrystallization at $220,240,260{ }^{\circ} \mathrm{C}$ (see $5 \times 5 \mathrm{~mm}^{2}$ square specimen, Figure $3 \mathrm{a}$ ) or $240,260,260{ }^{\circ} \mathrm{C}$ (see microbending specimens, Figure $3 \mathrm{~b}$ ). The ductility is very low, which is in accordance with the literature $[7,37,40]$, here $\varepsilon_{\mathrm{E}, \mathrm{r}}=0 \%$, and the comparability of $\mathrm{R}_{\mathrm{p} 0.01}{ }^{*}$ and $\mathrm{R}_{\mathrm{m}}{ }^{*}$ are further results. As a consequence, it could be assumed that strain hardening due to dislocation multiplication and Hall-Petch behavior is hardly possible. Hardening at low annealing temperatures, that occurs nevertheless as a result of the maximum values of $\mathrm{H}_{\mathrm{IT}}$ and $\mathrm{R}_{\mathrm{p} 0.01}{ }^{*}$, could have complementary reasons. Annealing hardening may in any case be a)

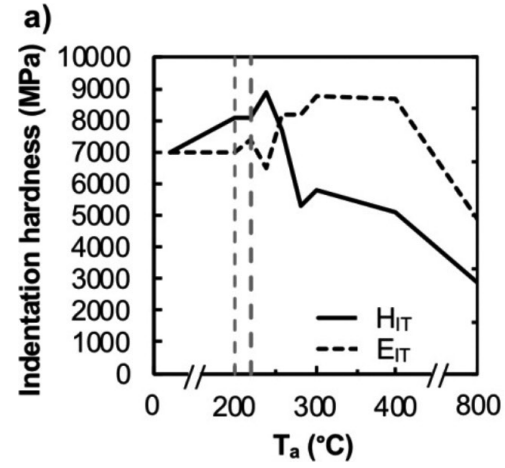

b)
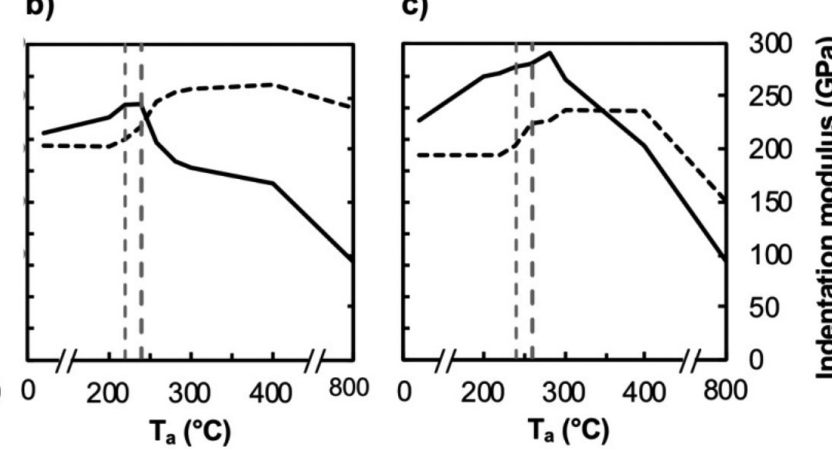

Figure 7: Indentation hardness $H_{I T}$ and indentation modulus $E_{I T}$ depending on annealing temperature $T_{a}$ of $5 \times 5 \mathrm{~mm}^{2}$ square specimens of DC-plated and annealed nickel-iron layers for a) R001-DC-0-5 with 5.7, b) R006-DC-0-3 with 8.8, and c) R007-DC-0-0.5 with 17.7 wt. $\%$ iron (grey vertical lines show the beginning of recovery (fine lines), and beginning of grain growth (bold lines measured through XRD)) a)

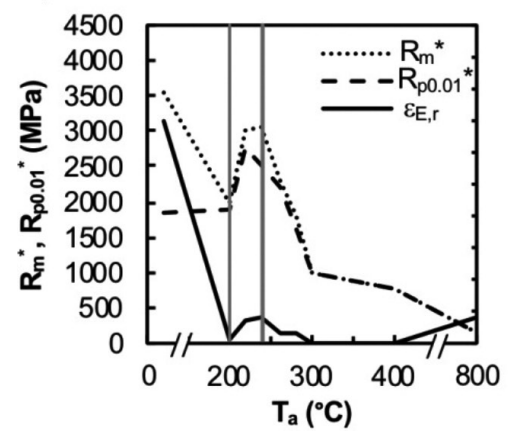

b)

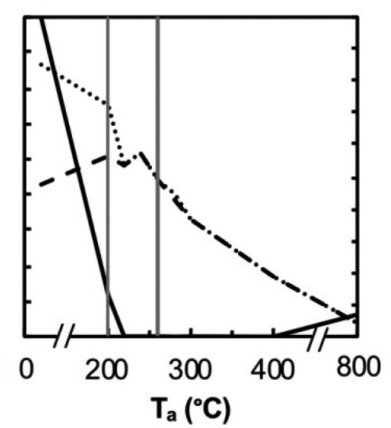

c)

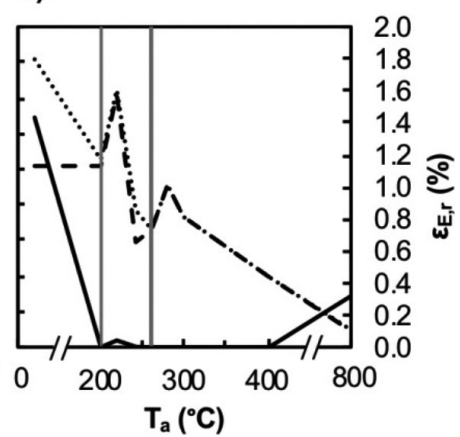

Figure 8: 0.01-\% offset bending yield strength $R_{p 0.01}{ }^{*}$, bending strength $R_{m}{ }^{*}$, and fracture strain on edge $\varepsilon_{E, r}$ depending on annealing temperature $T_{a}$ of microbending specimens of DC-plated, and annealed nickeliron layers a) R001-DC-0-5 with 5.7, b) R005-DC-0-1.5 with 13.4 and c) R007-DC-0-0.5 with 17.7 wt. $\%$ iron (grey vertical lines show the beginning of recovery (fine lines), and beginning of grain growth (bold lines measured through XRD)) 


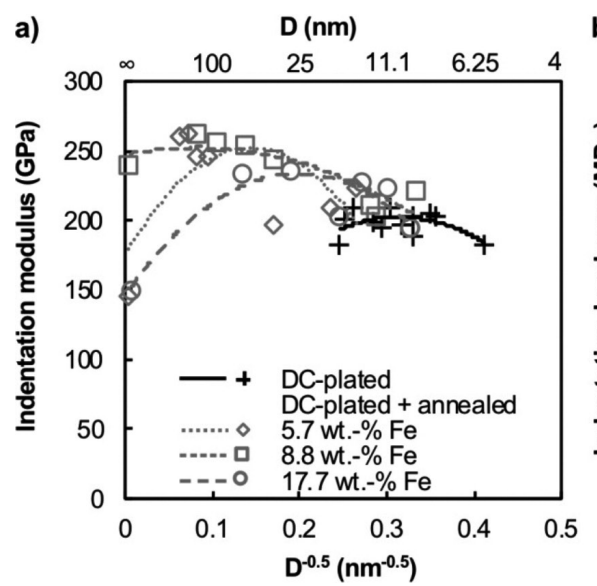

b)

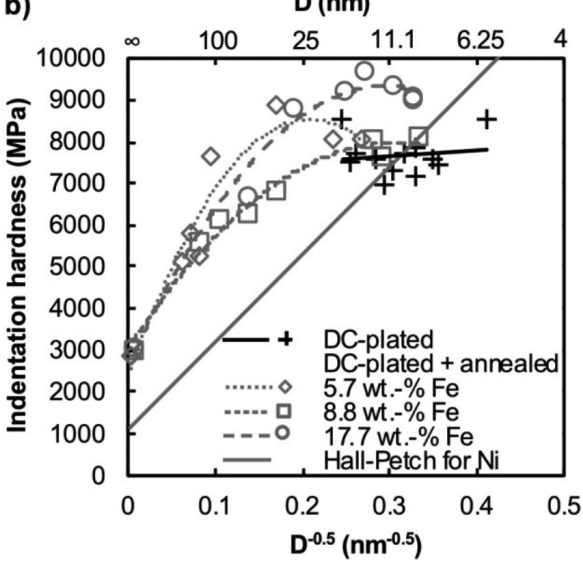

Figure 9: a) Indentation modulus $E_{I T}$, b) indentation hardness $H_{I T}$ with incorporated Hall-Petch line of DC-plated as well as of DC-plated, and annealed nickel-iron alloys depending on grain size D

caused by the segregation of impurities and dissolved atoms at the grain boundaries of the tested nanocrystalline nickel-iron alloys. This reflects the results and statements of other authors [29, 38, 41, 45].

$\mathrm{E}_{\mathrm{IT}}$ and $\mathrm{E}$ of the electrochemically deposited (crosses) and the electrochemically deposited and annealed specimens (open symbols) vs. the grain size can be seen in Figures $9 \mathrm{a}$ and 10a. Nanocrystalline grain sizes of about $10 \mathrm{~nm}$ even after low-temperature annealing display no significant influence on $\mathrm{E}_{\mathrm{IT}}$ (see Figure 9a and compare Figure 6). By contrast, E shows a decrease in values after low-temperature annealing (see Figures 6 and 10a). Increasing grain sizes from the beginning of primary recrystallization cause increasing values of $\mathrm{E}_{\mathrm{IT}}$ and to a lesser extent of E. Microstructures with grain sizes larger than about $100 \mathrm{~nm}$ reduce the values of $\mathrm{E}$. $\mathrm{E}_{\mathrm{IT}}$, on the contrary, only decreases after secondary recrystallization for grain sizes in the microcrystalline $(\mathrm{mc})$ range. In any case, the grain size changes from $\mathrm{nc}$ to $\mathrm{mc}$ as a result of the annealing processes and therefore reveals considerable differences in the modules. In the literature, influences of grain size on the Young's modulus of nickel and nickel-iron up to about $20 \mathrm{~nm}$ have been determined [55]. The authors report that above $20 \mathrm{~nm}$ there is practically no influence of grain size on the Young's modulus. In this study the microstructure, however, is in electrochemically deposited state without heat treatment [55].

Variations in iron content (5.7, 8.8, 13.5 and $17.7 \mathrm{wt} . \%)$, taking into account the considerable scatter, have no significant influence on the values of $E_{\mathrm{IT}}$ and also on the values of $\mathrm{E}$ (see open symbols, Figures 9a and 10a). Only two measured $\mathrm{E}_{\mathrm{IT}}$ values after secondary recrystallization at $800{ }^{\circ} \mathrm{C}$ for $\mathrm{mc}$ grain sizes differ considerably (see Figure 9a). According to [55], there is practically no significant influence on the modulus of elasticity for nickel-iron alloys between 0 and 20 wt.-\% Fe. Overall, the values of $\mathrm{E}_{\mathrm{IT}}$ are considerably greater than those of $\mathrm{E}$.

The Hall-Petch relationship is shown in Figure $9 \mathrm{~b}$ as indentation hardness $\mathrm{H}_{\mathrm{IT}}$ vs. $\mathrm{D}^{-0.5}$. This concerns the same nickel-iron layers as in Figure 4b with additional results of further specimens for electrochemical deposition.

Electrochemically deposited specimens (see DC-plated, crosses in Figure 9b) do not show any influence on the indentation hardness within the scatter for different iron contents and different grain sizes in the range of 6 to $17 \mathrm{~nm}$. The HP straight line for nickel according to Equation (2) is also plotted in Figure $9 \mathrm{~b}$ using the constants $\mathrm{k}_{\mathrm{H}}=21,000 \mathrm{MPa} \times \mathrm{nm}^{0.5}$ and $\mathrm{H}_{0}=1,100 \mathrm{MPa}$ [25]. A comparison with the measured values of DC-plated materials reveals that no HP behavior is discernible for the relatively narrow grain size range investigated [3, 10]. The mean value is on the HP line, but the values are not parallel to the line. Results in the literature confirm no HP behavior for hardness in the case of grain sizes below $25 \mathrm{~nm}$ [26, 55].

Annealed specimens after electrochemical deposition (DC-plated and annealed) are examined in a much wider grain size range from $\mathrm{nc}$ to $\mathrm{mc}$, from $9 \mathrm{~nm}$ to $74 \mu \mathrm{m}$ (see open symbols and dashed trend lines in Figure 9b). The indentation hardness for nearly all tested iron contents (5.7, 8.8 and $17.7 \mathrm{wt} . \% \mathrm{Fe}$ ) shifts from the HP line of nickel to higher values taking into account the scatter. None of the trend lines shown for the respective iron content is linear. The trend lines for the largest and smallest iron contents have a maximum that does not comply with the smallest grain size. For very small nc grain sizes and to a lesser extend the large mc grains, the values measured are closer to the Hall Petch line
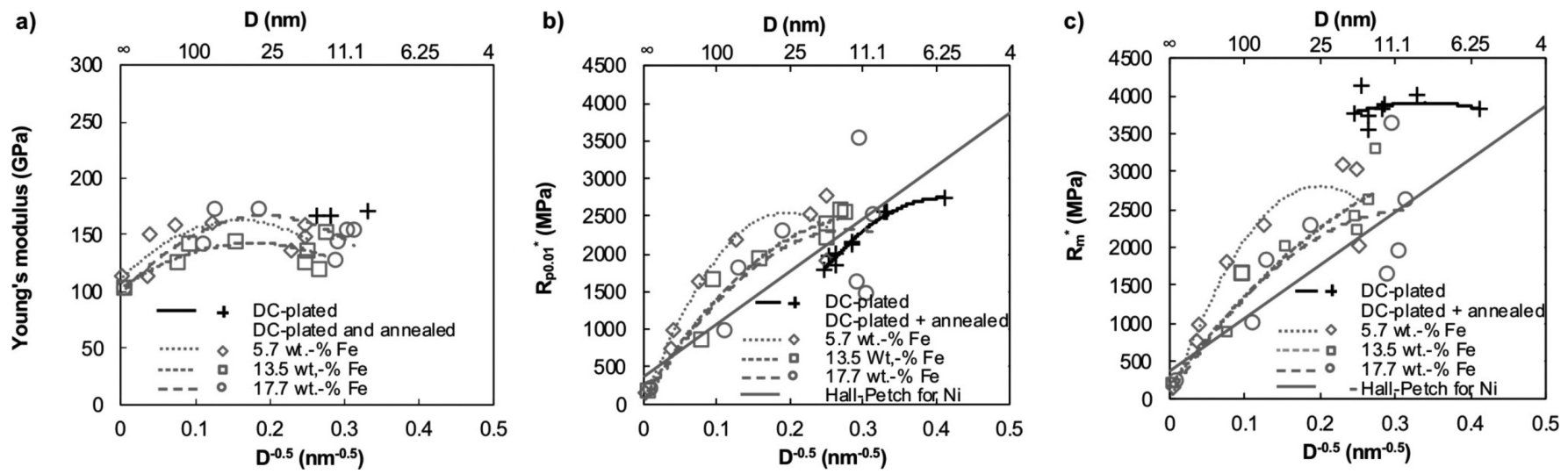

Figure 10: a) Young's modulus E, b) 0.01-\% offset bending yield strength $R_{p 0.01}{ }^{*}$, and c) bending strength $R_{m}{ }^{*}$ of microbending specimens vs. grain size D with incorporated Hall-Petch lines of DC-plated as well as DC-plated, and annealed nickel-iron alloys 
of nickel. Annealing treatment increases the hardness as compared to the electrochemically deposited state, most in specimens with the highest iron content of 17.7 wt.-\% (see Figure 9b, open circles). Very high hardness values are also reached for the smallest iron content 5.7 wt.-\% (see Figure 9b, open diamond). These are much higher than for $8.8 \mathrm{wt} .-\%$ Fe specimens (see Figure 9b, open square). However, this is not understood. Overall, indentation hardness depends on grain size for D > $25 \mathrm{~nm}$. The trend lines then are almost parallel to the HP straight line.

$\mathrm{R}_{\mathrm{p} 0.01}{ }^{*}$ vs. $\mathrm{D}^{-0.5}$ is shown in Figure 10b. According to Equation (1), the HP line for nickel is plotted where $\mathrm{k}_{\sigma}=7,000 \mathrm{MPa} \times \mathrm{nm}^{0.5}$ and $\sigma_{0}=370 \mathrm{MPa}$ [25].

For the electrochemically deposited nickel-iron alloys (DC-plated, crosses), the $\mathrm{R}_{\mathrm{p} 0.01}{ }^{*}$ values in Figure $10 \mathrm{~b}$ approximate the Hall-Petch line well with an investigated grain size range between 6 to $17 \mathrm{~nm}$ in contrast to the indentation hardness shown in Figure 9b. These $\mathrm{R}_{\mathrm{p} 0.01}{ }^{\text {* }}$ values are only slightly below those of the HP straight line. This applies to the selected edge strain rate of $10^{-3} \mathrm{~s}^{-1}$. At an elevated edge strain rate $0.1 \mathrm{~s}^{-1}$ not further considered here, the measuring points lie exactly on the Hall-Petch straight line [3]. A deviation to significantly lower values results occurs only for the smallest grain size determined as $5.9 \mathrm{~nm}$.

Annealed specimens after electrochemical deposition (DC-plated and annealed, open symbols) have $R_{p 0.01}$ * values usually shifted above the HP straight line (see Figure $10 \mathrm{~b})$. The $\mathrm{R}_{\mathrm{p} 0.01}{ }^{*}$ values are also higher than the values of electrochemically deposited (DC-plated, crosses) specimens with the same grain size, with two exceptions: For 17.7 wt.-\% Fe and annealing temperatures below or at the recrystallization temperature of 240 as well as $260^{\circ} \mathrm{C}$, at which the grain sizes are 11 and $12 \mathrm{~nm}$ (see Figure $3 b$ ) determined through XRD, corresponding to the minimum in Figure 8c. The maximum yield strength of $3,548 \mathrm{MPa}$ is observed for the specimen with highest iron content of $17.7 \mathrm{wt} .-\%$ after $220^{\circ} \mathrm{C}$ annealing treatment, resulting in $11.6 \mathrm{~nm}$ grain size. Annealing thus also increases yield strength but not quite as much as hardness (compare with Figure 9b). Specimens with the lowest iron content of 5.7 wt. $\%$ yield the highest strength at grain sizes larger than $16 \mathrm{~nm}$, more than those with 13.5 and 17.7 wt.-\% Fe (see Figure 10b). Grain sizes smaller than approx. $30 \mathrm{~nm}$ result in a significant decrease in the slope of the trend lines with $\mathrm{D}^{-0.5}$. A course of the trend lines to maximum is present for grain sizes below about $30 \mathrm{~nm}$ (5.7 wt. $\% \mathrm{Fe}$ ) and below $10 \mathrm{~nm}$ (13.5 and 17.7 wt.-\% Fe). However, HP behavior is absent at least for these small grain sizes for the heat-treated nickel-iron layers.

The bending strength of electrochemically deposited specimens (DC-plated, crosses) is independent of the measured grain size range between 6 and $17 \mathrm{~nm}$ (see Figure 10c). Due to the annealing treatments performed, $\mathrm{R}_{\mathrm{m}}{ }^{*}$ deteriorates overall (compare DC-plated and annealed, open symbols, with DC-plated specimens, crosses). By contrast, indentation hardness improves or increases as a result of annealing (see Figure $9 \mathrm{~b}$ ). In addition, $\mathrm{R}_{\mathrm{m}}{ }^{*}$ and $\mathrm{R}_{\mathrm{p} 0.01}{ }^{*}$ are nearly identical for the annealed specimens (DC-plated and annealed) over the entire $\mathrm{D}^{-0.5}$ range investigated. There are similar trend lines for $\mathrm{R}_{\mathrm{m}}{ }^{*}$ and $\mathrm{R}_{\mathrm{p} 0.01}$ * vs. $\mathrm{D}^{-0.5}$ in Figures $10 \mathrm{~b}$ and 10c. Fracture strain on the edge and consequently work hardening are nearly zero. Hall-Petch behavior of the annealed specimens (DCplated and annealed) is, if at all, most likely expected to be above $30 \mathrm{~nm}$.

The HP behavior of $\mathrm{R}_{\mathrm{p} 0.01}{ }^{*}$, measured in the range between 17 and $6 \mathrm{~nm}$, applies very well to the electrochemically deposited specimens (see Figure 10b). Deformation behavior above a critical grain size, in this case above $6 \mathrm{~nm}$, would have to be achieved by dislocation slip. According to other publications, the strength and hardness of electroplated NiFe-alloys follow Hall-Petch behavior [7, 15]. However, this has been obtained for large grain size ranges of 280 to $10 \mathrm{~nm}$ and 8,300 to $10 \mathrm{~nm}$. In our own results with the rather small grain size range 17 to $6 \mathrm{~nm}$, the HP behavior does not apply to the $\mathrm{R}_{\mathrm{m}}{ }^{*}$ and $\mathrm{H}_{\mathrm{IT}}$ of the electrochemically deposited specimens (see Figures $9 \mathrm{~b}$ and 10c), because hardness and bending strength are not necessarily suitable to characterize HP behavior due to higher plastic deformation, and, according to the definition, the HP relationship describes the yield strength as a function of grain size [56]. The $0.01 \%$ offset bending strength is, however, relatively close to the yield strength.

Hardening due to annealing has been observed as well in results from the literature [29, 37, 38, 41, 45]. The present results show an increase in $\mathrm{H}_{\mathrm{IT}}$ and $\mathrm{R}_{\mathrm{p} 0.01}{ }^{*}$ as compared to the electrochemically deposited state due to low temperature annealing treatment (see Figures $9 \mathrm{~b}$ and $10 \mathrm{~b}$ ). This applies to all investigated iron contents.
Maximum values of $\mathrm{H}_{\mathrm{IT}}$ and $\mathrm{R}_{\mathrm{p} 0.01}$ * were determined slightly before, shortly after or at the beginning of recrystallization temperature (see Figures 3, 7 and 8). Recovery, however has already begun in all cases (see Figure 2). It should be noted that grain size and microstrain measurements using XRD provide only mean values. Thus, at maximum hardness or maximum $0.01-\%$ offset bending yield strength, the mean grain sizes here are almost unchanged or slightly larger, possibly with a bimodal structure. The highest iron content of $17.7 \mathrm{wt} .-\%$ causes the strongest increase in hardness through low-temperature annealing. In one case, this also applies to $\mathrm{R}_{\mathrm{p} 0.01}{ }^{*}$. From the maximum values, all hardness and strength values drop with rising annealing temperatures (see Figures 7 and 8). One reason for this is the relatively low thermal stability of the microstructure of the nickeliron alloys (see Figures 2 and 3).

Hall-Petch behavior and the linear dependence of strength and hardness of $\mathrm{D}^{-0.5}$ is not visible in annealed specimens with grain sizes below about $30 \mathrm{~nm}$ (see Figures $9 \mathrm{~b}, 10 \mathrm{~b}$ and 10c). Grain sizes larger than $30 \mathrm{~nm}$ tend to show an approx. linear characteristic with $\mathrm{D}^{-0.5}$. For the various iron contents, starting from nc crystals after low-temperature annealing, indentation hardness and strength converge, respectively, to approx. the same values for the microcrystalline structures after raising the annealing temperature up to $800{ }^{\circ} \mathrm{C}$. The increase in strength and hardness by annealing at low temperatures as well as a decrease in ductility could be caused by the segregation of sulfur and iron atoms, for example, at the grain boundaries [37]. In addition it is also believed, that the reduction of microstrains and thus of lattice defects such as dislocation density stabilize the grain boundaries and make the material stronger and more brittle, especially at low annealing temperatures [29, 40]. Hardening mechanisms change through annealing. In a solely electroplated condition, dislocation gliding can be assumed according to the HP behavior down to grain sizes of almost $6 \mathrm{~nm}$. After low-temperature annealing, hardening mechanisms of the grain boundaries may also occur, which are inhibited by segregations. According to the literature [38], as a result of the heat treatment, both may have a strengthening effect, Hall-Petch behavior as well as additional precipitation hardening. This could also be the case here for $R_{p 0.01}{ }^{\star}$. The HP line from Equation (1) [25] is quite parallel and close to the conditions of electrochemi- 
cal deposition with nc grains (crosses) and close to states of electroplated and annealed ufg grains as well as to states of $\mathrm{mc}$ grains (see open symbols, Figure 10b) of secondary recrystallization. Most other $\mathrm{R}_{\mathrm{p} 0.01}{ }^{*}$ values are above the HP straight line. These excess strength values could be explained by the effects of segregations and of reduced microstrains [29].

When considering indentation hardness, an HP straight line for nickel according to Equation (2) provides the basis [25] (see Figure 9b). As mentioned, the values of electrochemically deposited nickel-iron are in the middle of the HP straight line (crosses). The individual values do not show any grain size dependence. $\mathrm{H}_{\mathrm{IT}}$ values, as result of the annealing, are shifted considerably above the HP straight line. For the smallest grain sizes, the $\mathrm{H}_{\mathrm{IT}}$ values of the HP straight lines partially approach. This behavior is to some extent similar to that of $\mathrm{R}_{\mathrm{p} 0.01}{ }^{*}$ given in Figure $10 \mathrm{~b}$. In contrast to $\mathrm{R}_{\mathrm{p} 0.01}{ }^{*}, \mathrm{H}_{\mathrm{IT}}$ values for the largest grain sizes are clearly distant from the HP straight line. Hence, the alloying of nickel with iron and the heat treatments exhibit hardening effects. $\mathrm{H}_{\mathrm{IT}}$ and $\mathrm{R}_{\mathrm{p} 0.01}{ }^{*}$ are maximum due to the small grains of 30 to $10 \mathrm{~nm}$ and are likely due to the segregations at the grain boundaries as well as due to the reduction of the microstrains. Because of the low thermal grain boundary stability of the investigated alloys, an increase in hardness, as with the $\mathrm{D}^{-1}$ dependence of [29], cannot be observed.

At higher annealing temperatures, larger grains and larger precipitates are formed owing to the low thermal stability of the segregations. As a consequence, hardness and strength decrease. Fracture strain on edge remains very low, as the dislocation density is very low due to the low microstrain measured and the precipitates can act on the embrittling. Presumably increasing the similarity of the microstructure for different iron contents as a result of high annealing temperatures leads to identical mechanical properties.

\section{Summary and Conclusions}

Within this study, the microstructure and mechanical properties of electrochemically deposited and subsequently annealed nickel-iron alloys have been investigated. Nickel-iron layers are deposited on copper discs using direct current. Defined alloying and microstructural parameters such as iron content, grain size and microstrain are systematically influenced via current density $[3,10]$. In characterizing thermal behavior, the effect of heat treatment on the microstructure and the associated mechanical properties have been examined. XRD microstructure analyses, instrumented indentation and microbending tests were performed before and after heat treatment.

If variation in the annealing temperature is taken into account, the following changes can be observed in the microstructure and in the mechanical properties:

- The microstructures of the nc-nickeliron alloys investigated with 5.7 to 17.7 wt.-\% Fe are thermally rather unstable. Reduction in microstrain initiates before grain growth starts. Recovery therefore begins at 200 to $240{ }^{\circ} \mathrm{C}$. Primary recrystallization starts at 220 to $260{ }^{\circ} \mathrm{C}$. A higher iron content has a slightly improved thermal stabilizing effect. After recrystallization, precipitates with higher sulphur contents can be observed [10, 47]. Presumably, already before recrystallization and before recovery, dissolved atoms of impurities or alloys occur at the grain boundaries as described in the literature [42]. These and decreasing microstrains have some stabilizing effect on the grain boundaries and the microstructure and thus influence mechanical behavior.

- The modulus of indentation as well as Young's modulus are not significantly influenced by the iron contents investigated, both after electrochemical deposition and after the respective annealing treatments. The values of the indentation module $\mathrm{E}_{\mathrm{IT}}$ are always higher than those of Young's modulus E. After electrochemical deposition and before annealing, $\mathrm{E}_{\mathrm{IT}}$ is approx. $200 \mathrm{GPa}$ and $\mathrm{E}$ is approx. $165 \mathrm{GPa}$. $\mathrm{E}_{\mathrm{IT}}$ and $\mathrm{E}$ change from the beginning of the recovery. $\mathrm{E}_{\mathrm{IT}}$ rises up to $300{ }^{\circ} \mathrm{C}$ to a plateau of about $250 \mathrm{GPa}$ and drops significantly beyond $400{ }^{\circ} \mathrm{C}$ down to $145 \mathrm{GPa}$ for the specimens annealed at $800^{\circ} \mathrm{C}$. E reaches a maximum for 260 or $280^{\circ} \mathrm{C}$ of approx. $160 \mathrm{GPa}$ and then considerably decreases for $800{ }^{\circ} \mathrm{C}$ to about $105 \mathrm{GPa}$. This is well below the initial electrochemical deposition values.

- Indentation hardness $\mathrm{H}_{\mathrm{IT}}$ rises before measuring the beginning of recovery. The maximum of $\mathrm{H}_{\text {IT }}$ is achieved by annealing directly after or at the beginning of recrystallization. $\mathrm{H}_{\text {IT }}$ subsequently decreases and after secondary recrystallization at $800{ }^{\circ} \mathrm{C}$ drops significantly, down to $40 \%$ of the initial value after electrochemical deposition. Specimens with a higher iron content of 17.7 wt.-\% yield higher hardness values.

- The $0.01-\%$ offset bending yield strengths $\mathrm{R}_{\mathrm{p} 0.01}{ }^{*}$ change less until the beginning of the recovery. The maximum values of $\mathrm{R}_{\mathrm{p} 0.01}{ }^{*}$ for all three iron contents occur before the beginning of the recrystallization. Subsequently, the $\mathrm{R}_{\mathrm{p} 0.01}{ }^{*}$ values decrease, and, after $800{ }^{\circ} \mathrm{C}$ annealing, reach 8 to $9 \%$ of the initial values after the electrochemical depositions.

- Extremely high bending strengths $\mathrm{R}_{\mathrm{m}}$ * of the electrochemically deposited state already decrease rapidly after annealing at low temperatures of $200{ }^{\circ} \mathrm{C}$. They are identical to $\mathrm{R}_{\mathrm{p} 0.01}{ }^{*}$ for further increasing annealing temperatures. Accordingly, the fracture strain on the edge of electrochemically deposited specimens already decreases after annealing at $200{ }^{\circ} \mathrm{C}$ to zero and increases only slightly after annealing at $800{ }^{\circ} \mathrm{C}$.

- Hardening at low temperature annealing at the beginning of recrystallization is shown by increases in $\mathrm{H}_{\mathrm{IT}}$ and $\mathrm{R}_{\mathrm{p} 0.01}{ }^{*}$ as compared to the electrochemically deposited initial state. As described in the literature, this might be associated with segregations at the grain boundaries, and, after initial recovery, with a partial reduction of microstrains and dislocations. The resulting stabilization of the grain boundaries impedes plastic deformation and increases $\mathrm{H}_{\mathrm{IT}}$ and $\mathrm{R}_{\mathrm{p} 0.01}{ }^{*}$, but reduces $\mathrm{R}_{\mathrm{m}}{ }^{*}$ and ductility.

Taking into account the grain sizes of the annealed microstructures, determined by X-ray diffraction, the following results have been obtained for the mechanical properties of the nickel-iron alloys investigated:

- For the indentation modulus $\mathrm{E}_{\mathrm{IT}}$ after annealing, values show an increase due to modified microstructures during increasing grain sizes from the nc range of approx. $10 \mathrm{~nm}$ (from $220^{\circ} \mathrm{C}$ ) to the ufg range of approx. $250 \mathrm{~nm}\left(400^{\circ} \mathrm{C}\right)$. Only after secondary recrystallization at $800{ }^{\circ} \mathrm{C}$ in the microcrystalline range does $\mathrm{E}_{\mathrm{IT}}$ drop, in some cases significantly. The Young's modulus E also reflects changes with the heat treated microstructures and grain sizes, but is different from $\mathrm{E}_{\mathrm{IT}}$.

- Hall-Petch (HP) behavior is observed only for $\mathrm{R}_{\mathrm{p} 0.01}$ * with electrochemically deposited specimens for grain sizes in the range of 6 to $17 \mathrm{~nm}$ investigated.

- The HP straight line [25] corresponds well with the $R_{p 0.01}{ }^{*}$ values of the electrochemically deposited specimens and 
moderately with the values of the specimens annealed at higher temperatures with grain sizes in the ufg and $\mathrm{mc}$ range. All $\mathrm{R}_{\mathrm{p} 0.01}$ * values above the HP straight line indicate strengthening in addition to grain size effects by segregations and lower microstrains in the material. The curve for the bending strength $R_{m}{ }^{*} v s$. $\mathrm{D}^{-0.5}$ is very similar to that of $\mathrm{R}_{\mathrm{p} 0.01}{ }^{*}$. By definition, however, the HP relationship only applies to the yield strength.

- In the case of indentation hardness $\mathrm{H}_{\mathrm{IT}}$, only the mean value of the electrochemically deposited specimens tested corresponds to the HP straight line [25]. Any other $\mathrm{H}_{\mathrm{IT}}$ values of the annealed specimens deviate from the HP straight line to higher values and show an almost linear behavior for grain sizes $>30 \mathrm{~nm}$ only.

In all, electroplated nanocrystalline nickeliron alloys exhibit excellent strength and hardness values because of their extremely small grains. Strength $R_{p 0.01}$ * increases with decreasing grain size according to HP. With a critical grain size, here $6 \mathrm{~nm}, \mathrm{R}_{\mathrm{p} 0.01}{ }^{\text {* }}$ deviates to smaller values from the HP straight line. Thereafter, as described in the literature, grain boundary deformation mechanisms dominate.

By contrast, specimens annealed at low temperatures with very small grain sizes of about $10 \mathrm{~nm}$ manifest a deviation from the HP straight line to higher values for $\mathrm{R}_{\mathrm{p} 0.01}{ }^{\text {* }}$ and for hardness. This occurs around the beginning of the recrystallization temperature and after the recovery temperature, each determined through XRD. The behavior referred to in the literature as hardening annealing is explained by a decrease in microstrain and an anchoring of the grain boundaries by impurity and alloy atoms as well as by ultra-fine precipitations and additionally acts to grain size hardening. Due to the low thermal stability of nickel-iron alloys, precipitates and grains increase at still low annealing temperatures and strength and hardness decrease.

Significantly higher thermal stability with good mechanical properties can be achieved by alloying nickel with phosphorus, molybdenum, tungsten, or yttrium as well as composite materials with embedded nanoparticles.

\section{Ackowledgement}

The authors would like to thank the BMBF and the "Stiftung Rheinland-Pfalz für Innovation" for the project's financial support. Thanks go to the company Micromotion $\mathrm{GmbH}$ in Mainz Gonsenheim, Germany for the electrochemical deposition of nickeliron layers on copper discs

\section{References}

1 H. Gleiter: Nanocrystalline materials, Progress in Materials Science 33 (1989), pp. 223-315 DOI:10.1016/0079-6425(89)90001-7

2 S. H. Wang: Nanostructured Metals and Alloys, Woodhead Publishing Limited, Cambridge, UK (2011)

DOI:10.1016/B978-1-84569-670-2.50028-9

3 J. E. Hoffmann, M.-T. Schmitt, D. Eifler, T. Beck, P. Klär, M. Saumer: Bending deformation and indentation hardness of electrochemical deposited nanocrystalline nickel-iron alloys, Materials Testing 60 (2018), pp. 1041-1049 DOI:10.3139/120.111259

4 M. Dao, L. Lu, R. J. Asaro, J. T. M. De Hosson, E. Ma: Toward a quantitative understanding of mechanical behavior of nanocrystalline metals, Acta Materialia 55 (2007), pp. 4041-4065 DOI:10.1016/j.actamat.2007.01.038

5 C. C. Koch, K. M. Youssef, R. O. Scattergood, K. L. Murty: Breakthroughs in optimization of mechanical properties of nanostructured metals and alloys, Advanced Engineering Materials 7 (2005), pp. 787-794 DOI:10.1002/adem.200500094

6 B. L. Boyce, H. A. Padilla II: Anomalous fatigue behavior and fatigue-induced grain growth in nanocrystalline nickel alloys, Metallurgical and Materials Transactions A 42 (2011), pp. 1793-1804 DOI:10.1007/s11661-011-0708-X

7 F. Ebrahimi, H. Li: The effect of annealing on the deformation and fracture of a nanocrystalline fcc metal, Journal of Materials Science 42 (2007), pp. 1444-1454 DOI:10.1007/s10853-006-0969-8

8 L. Lu, M. L. Sui, K. Lu: Superplastic extensibility of nanocrystalline copper at room temperature, Science (New York, N. Y.) 287 (2000), pp. 1463-1466

DOI:10.1126/science.287.5457.1463

9 R. Slatter, R. Degen: The micro harmonic drive: A high precision gear system miniaturized by direct-LIG, in Proc. of the $4^{\text {th }}$ Euspen International Conference, Glasgow, Scotland (2004), pp. 13-14

10 M.-T. Schmitt: Characterization of Electrochemically Produced Nanocrystalline NickelIron Alloys, Dissertation TU Kaiserslautern, Germany (2014) (in German), Charakterisierung galvanisch hergestellter nanokristalliner Nickel-Eisen-Legierungen

11 D. P. Arnold, M. Saumer, Y-K. Yoon: Additive Processes in Metals, R. Ghodssi, P. Lin (Eds.): MEMS Materials and Processes Handbook, Springer Science-Business Media, LLC, New York, 2011, pp. 137-191 DOI:10.1007/978-0-387-47318-5

12 A. M. Rashidi, A. Amadeh: The effect of current density on the grain size of electrodeposited nanocrystalline nickel coatings, Surface and Coatings Technology 202 (2008), pp. 3772-3776 DOI:10.1016/j.surfcoat.2008.01.018

13 Y. Marita, I. I. Yaacob: Structural characterization of electrodeposited nickel-iron alloy films,
Materials Science Forum 654-656 (2010), pp. 2430-2433

DOI:10.4028/www.scientific.net/ MSF.654-656.2430

14 M. Teutsch: Development of electrochemically deposited LIGA-Ni-Al for high-temperature MEMS applications, Schriftenreihe des Instituts für Angewandte Materialien, Karlsruher Institut für Technologie 24, Germany (2013) (in German)

15 R. Schwaiger, J.-T. Reszat, K. Bade, J. Aktaa, O. Kraft: A combined microten-sile testing and nanoindentation study of the mechanical behavior of nanocrystalline LIGA Ni-Fe, International Journal of Materials Research 100 (2009), pp. 68-75 DOI:10.3139/146.101785

16 U. Kirsch: Electrochemical deposition of lowstress nickel-iron alloy layers and their properties for components of microsystem technology, Dissertation, Albert-Ludwig-Universität, Freiburg, Germany (2000), (in German), Elektrochemische Abscheidung von spannungsarmen Nickel-Eisen-Legierungsschichten und ihre Eigenschaften für Bauteile der Mikrosystemtechnik

17 A. M. El-Sherik, U. Erb: Synthesis of bulk nanocrystalline nickel by pulsed electrodeposition, Journal of Materials Science 30 (1995), pp. 5743-5749 DOI:10.1007/BF00356715

18 A. M. Pillai, A. Rajendra, A. K. Sharma: Pulse electrodeposition of nanocrystalline nickel on AA 6061 for space applications, Transactions of the Institute of Metal Finishing 90 (2012), pp. 44-51

DOI:10.1179/174591911X13165161228286

19 A. Knödler, E. Raub: Einfluss der Molekularstruktur organischer Schwefelverbindungen auf die inneren Spannungen von Nickelniederschlägen, Metalloberfläche Angewandte Elektrochemie 27 (1973), pp. 48-59

20 J. E. Hoffmann, K. Bedner, H. Clemens, R. Degen, F. Giro, U. Kirsch, M.-T. Schmitt, M. Saumer: The influence of electroplating parameters on the conditions of deposited nickel-iron coatings, Materialwissenschaft und Werkstofftechnik 39 (2008), pp. 209-216 DOI:10.1002/mawe.200800286

21 W. Immel: Organische Inhibitoren in galvanischen Bädern, Metalloberfläche 48 (1994), pp. 466-469

22 A. Godon, J. Creus, S. Cohendoz, E. Conforto, X. Feaugas, P. Girault, C. Savall: Effects of grain orientation on the Hall-Petch relationship in electrodeposited nickel with nanocrystalline grains, Scripta Materialia 62 (2010), pp. 403-406 DOI:10.1016/j.scriptamat.2009.11.038

23 H. Q. Li, F. Ebrahimi: An investigation of thermal stability and microhardness of electrodeposited nanocrystalline nickel-21\% iron alloys, Acta Materialia 51 (2003), pp. 3905-3913 DOI:10.1016/S1359-6454(03)00215-5

24 H. Li, F. Ebrahimi: Synthesis and characterization of electrodeposited nanocrystalline nickeliron alloys, Materials Science and Engineering A 347 (2003), pp. 93-101 DOI:10.1016/S0921-5093(02)00586-5 
25 J. E. Carsley, J. Ning, W. W. Milligan, S. A. Hackney, E. C. Aifantis: A simple mixtures-based model for the grain size dependence of strength in nanophase metals, NanoStructured Materials 5 (1995), pp. 441-448 DOI:10.1016/0965-9773(95)00257-F

26 A. M. El-Sherik, U. Erb, G. Palumbo, K. T. Aust: Deviations from Hall-Petch behaviour in as-prepared nanocrystalline nickel, Scripta Metallurgica et Materialia 27 (1992), pp. $1185-1188$ DOI:10.1016/0956-716X(92)90596-7

27 S. Cheng, E. Ma,. Y. M. Wang, L. J. Kecskes, K. M. Youssef, C. C. Koch, U. P. Trociewitz, K. Han: Tensile properties of in situ consolidated nanocrystalline copper, Acta Materialia 53 (2005), pp. 1521-1533 DOI:10.1016/j.actamat.2004.12.005

28 H. S. Kim, Y. Estrin, M. B. Bush: Plastic deformation behavior of fine-grained materials, Acta Materialia 48 (2000), pp. 493-504 DOI:10.1016/S1359-6454(99)00353-5

29 J. Hu, Y. N. Shi, X. Sauvage, G. Sha, K. Lu: Grain boundary stability governs hardening and softening in extremely fine nanograined metals, Science 355 (2017), pp. 1292-1296 DOI:10.1126/science.aal5166

30 J. A. Sharon, H. A. Padilla II, B. L. Boyce: Interpreting the ductility of nanocrystalline metals, Journal of Materials Research 28 (2013), pp. 1539-1552 DOI:10.1557/jmr.2013.139

31 H. Li, F. Ebrahimi: Transition of deformation and fracture behaviors in nanostructured face-centered-cubic metals, Applied Physics Letters 84 (2004), pp. 4307-4309 DOI: $10.1063 / 1.1756198$

32 U. Klement, U. Erb, A. M. El-Sherik, K. T. Aust: Thermal stability of nanocrystalline $\mathrm{Ni}$, Materials Science and Engineering A203 (1995), pp. 177-186 DOI:10.1016/0921-5093(95)09864-X

33 M. Thuvander, M. Abraham, A. Cerezo, G. D. W. Smith: Thermal stability of electrodeposited nanocrystalline nickel and iron-nickel alloys, Materials Science and Technology 17 (2001), pp. 961-970 DOI:10.1179/026708301101510799

34 N. Dong, C. Zhang, J. Li, P. Han: Synthesis and thermal stability of nanocrystalline nickel coatings by direct current electrodeposition, Rare Metal Materials and Engineering 45 (2016), pp. 885-888 DOI:10.1016/S1875-5372(16)30093-5

35 J. Kacher, K. Hattar, I. M. Robertson: Initial texture effects on the thermal stability and grain growth behavior of nanocrystalline $\mathrm{Ni}$ thin films, Materials Science and Engineering A 675 (2016), pp. 110-119 DOI:10.1016/j.msea.2016.08.045

36 F. Czerwinski, H. Li, M. Megret, J. A. Szpunar, D.G Clark, U. Erb: The evolution of texture and grain size during annealing of nanocrystalline $\mathrm{Ni}-45 \%$ Fe electrodeposits, Scripta Materialia 37 (1997), pp. 1967-1972 DOI:10.1016/S1359-6462(97)00390-4

37 Y. M. Wang, S. Cheng, Q. M. Wei, E. Ma, T. G. Nieh, A. Hamza: Effects of annealing and impurities on the tensile properties of electrodeposited nanocrystalline Ni, Scripta Materialia 51 (2004), pp. 1023-1028 DOI:10.1016/j.scriptamat.2004.08.015

38 K. A. Darling, L. J. Kecskes, M. Atwater, J. Semones, R. O. Scattergood, C. C. Koch: Thermal stability of nanocrystalline nickel with yttrium additions, Journal of Materials Research 28 (2013), pp. 1813-1819 DOI:10.1557/jmr.2013.9

39 U. Klement, M. da Silva, G. Hibbard: Therma stability of nanocrystallieb $\mathrm{Ni}$ - and Co-based pulsed current electrodeposits: correlation of calorimetric measurements and microstructure development upon annealing, Transactions of the IMF 95 (2017), pp. 20-24 DOI:10.1080/00202967.2017.1263475

40 T. Nagoshi, T.-F. Chang, T. Sato, M. Sone: Effect of annealing on mechanical properties of nickel electrodeposited unsing supercritical $\mathrm{CO}_{2}$ emulsion evaluated by micro-compression test, Microelectronic Engineering 153 (2016), pp. 101-104 DOI:10.1016/j.mee.2016.02.017

41 N. Zhang, S. B. Jin, G. Sha, J. K. Yu, X. C. Cai, C. C. Du, T. D. Shen: Segregation induced hardening in annealed nanocrystalline Ni-Fe alloy, Materials Science and Engineering A 735 (2018), pp. 354-360 DOI:10.1016/j.msea.2018.08.061

42 C. C. Koch, R. O. Scattergood, K. A. Darling: Stabilization of nanocrystalline grain sizes by solute additions, Journal of Materials Science 43 (2008), pp. 7264-7272 DOI: $10.1007 / \mathrm{s} 10853-008-2870-0$

43 U. Klement, M. da Silva: Thermal stability of electrodeposited nanocrystalline Ni- and Co-based materials, Journal of Iron and Steel Research, International 24 (2007), pp. 173-178 DOI:10.1016/S1006-706X(08)60074-6

44 G. K. Rane, D. Apel, U. Welzel, E. J. Mittemeijer: The microstructural evolution and thermal stability of nanocrystalline ball-milled Ni-15 at.-\% W powder, Jornal of Materials Research 28 (2013), pp. 873-886 DOI:10.1557/jmr.2012.442

45 T. D. Shen, S. W. Xin, B. R. Sun: Influence of annealing on the mechanical property of ironand nickel-based nanocrystalline alloys, Materials Science and Engineering A 627 (2015), pp. 139-144 DOI:10.1016/j.msea.2014.12.116

46 T. Ungár, I. Dragomir, A. Révész, Á. Borbély: The contrast factors of dislocations in cubic crystals: the dislocation model of strain anisotropy in practice, Journal of Applied Crystals 32 (1999), pp. 992-1002 DOI:10.1107/S0021889899009334

47 M.-T. Schmitt, J. E. Hoffmann, D. Eifler: Microstructural parameters and their effect on the indentation hardness of electrodeposited and annealed nickel-iron micro-specimens, Advanced Engineering Materials 15 (2013), pp. $442-448$ DOI:10.1002/adem.201200253

48 T. Ungar, E. Schafler, J. Gubicza: Microstructure of bulk nanomaterials determined by $x$-ray line-profile analysis (2009), M. J. Zehetbauer, Y. T. Zhu (Eds.): Bulk Nanostructured Materials, WILEY-VCH, Weinheim (2009), pp. 361-386 DOI:10.1002/9783527626892.ch17
49 H. Neff: Grundlagen und Anwendung der Röntgen-Feinstruktur-Analyse, R. Oldenbourg, München (1962)

50 G. Petzow: Metallographisches, keramographisches, plastographisches Ätzen, Gebrüder Borntraeger Verlag, Berlin (1994)

51 V. Valvoda, M. Järvinen: On the Harris texture index, Powder Diffraction 5 (1990), pp. 200-203 DOI:10.1017/S0885715600015797

52 PCPDFWIN, JCPDS, International Centre for Diffraction Data, V 2.6 (2003)

53 E. Macherauch, H.-W. Zoch: Praktikum in Werkstoffkunde, Springer Verlag, Berlin (2014) DOI:10.1007/978-3-658-05038-2

54 J. Rösler, H. Harders, M. Bäker: Mechanisches Verhalten der Werkstoffe, Springer Vieweg Verlag, Wiesbaden (2016) DOI:10.1007/978-3-658-13795-3

55 J. D. Giallonardo, U. Erb, K. T. Aust, G. Palumbo: The influence of grain size and texture on the young's modulus of nanocrystalline nickel and nickel-iron alloys, Philosophical Magazine 91 (2011), pp. 4594-4605 DOI:10.1080/14786435.2011.615350

56 N. J. Petch: The cleavage strength of polycrystals, Journal of the Iron and Steel Institute (1953), pp. 25-28

\section{Bibliography}

DOI 10.3139/120.111475

Materials Testing

62 (2020) 3, pages 225-241

(C) Carl Hanser Verlag GmbH \& Co. KG ISSN 0025-5300

\section{The authors of this contribution}

Prof. Dr.-Ing. Joachim Ernst Hoffmann, born in 1953, studied Mechanical Engineering at the University of Karlsruhe, Germany from 1975 to 1979. From 1979 to 1984, he studied and received his Doctorate at the Institute for Materials Science I. 1985 to 1988 he worked as a group leader on the development of electronic fuel pumps at the company Robert Bosch GmbH in Stuttgart, Germany. In 1988 he was appointed to Chair at the University of Applied Sciences Kaiserslautern, Germany in the Department of Materials Science.

Dr.-Ing. Martin -T. Schmitt, born in 1971, studied Mechanical Engineering at University of Applied Science in Kaiserslautern, Germany where he completed his Dipl.-Ing. (FH) in 1999. After several years in industry, he started basic research at the University of Applied Sciences in Kaiserslautern. In 2014 he received his Dr.-Ing. degree from the Technical University Kaiserslautern. Since 2014 he works for the Voestalpine Böhler Welding Fontargen GmbH as Manager Global R\&D Brazing.

Prof. Dr.-Ing. habil. Dietmar Eifler, born in 1949, received his PhD at the University of Karlsruhe. From 1991 to 1994 he was Professor at the University of Essen. From 1994 until 2015 he was Professor and from 2015 to 2017 Senior Research Professor at the Institute of Materials Science and Engineering at the University of Kaiserslautern. His research activities are focused on the characterization of the fatigue behavior of metallic materials using mechanical, electrical, 
magnetic, acoustic as well as thermal measuring techniques in the LCF-, HCF- and VHCF realm.

Prof. Dr.-Ing. Tilmann Beck, born 1967, studied Mechanical Engineering at the University of Karlsruhe (now KIT), Germany, from 1989 to 1995. He received his Doctoral degree in 1999 with a research work on isothermal thermomechanical fatigue of fiber-reinforced aluminum alloys. From 1999 to 2006 he was head of the Near Service Loadings Lab at the Institute of Materials Science and Engineering at the University of Karlsruhe. 2007 he joined the Institute of Energy and Climate Research IEK-2 at the Forschungszentrum Jülich, Germany, as Head of the Department "Metallic Structural Materials". From 2008 to 2014 he was Professor of High Temperature Materials Mechanics at RWTH Aachen University, Germany and from 2011-2014 Head of the Materials Mechanics section of IEK-2. In 2014 he became Full Professor and chair of Materials Science and Engineering at the Technical University Kaiserslautern, Germany.

Prof. Dr.-Ing. Torsten Hielscher, born in 1977, studied Industrial Engineering at the TU Kaiserslautern, Germany. From 2003 to 2008 he worked as a Research Assistant at the Institute for Manufacturing Technology and Production Systems (FBK) at the TU Kaiserslautern, Germany. He received his Doctoral degree in Engineering in 2008. From 2005 to 2008, he headed the research group "Manufacturing Technology" at FBK. Afterwards, he worked at Schaeffler Technologies AG in Homburg, Germany, as Head of the Department for Manufacturing Technologies and Process Engineering. Since 2012 he has been Professor in the field of Production and Manufacturing Technology at the University of Applied Sciences Kaiserslautern (Hochschule Kaiserslautern), Germany. He is a founding member of the Institute for Quality, Modeling, Manufacturing, and Materials $\left(\mathrm{QM}^{3}\right)$, which was established in 2019 at the
University of Applied Sciences Kaiserslautern. His research focuses on the control and optimization of manufacturing process chains. There, he mainly deals with cutting processes with geometrically defined cutting edges, especially with respect to chip and burr formation as well as technical surfaces.

Dr.-Ing. Tina Eyrisch, born in 1978, studied Mechanical Engineering at TU Kaiserslautern, Germany. In 2004, she became a Research Assistant at the Institute for Manufacturing Technology and Production Systems (FBK) at TU Kaiserslautern, Germany. She received her Doctoral degree in Engineering in 2009. From 2011 to 2014 she was a Junior Professor in the field of Cutting at FBK. She is currently working as a visiting scientist at the Institute for Quality, Modeling, Manufacturing, and Materials $\left(\mathrm{OM}^{3}\right)$ at the University of Applied Sciences Kaiserslautern (Hochschule Kaiserslautern). She concentrates on the machinability of metallic and non-metallic materials and technical cleanliness.

Prof. Dr.-Ing. Peter Starke, born in 1977, studied Mechanical Engineering at TU Kaiserslautern, Germany. Since 2002, he has been a research assistant at the Institute of Materials Science and Engineering (WKK) at the TU Kaiserslautern, Germany. He received his Doctoral degree in Engineering in 2007 working on "The fatigue life calculation of metallic materials under constant amplitude loading and service loading”. From 2007 to 2012 he headed the research group "Fatigue life calculation" at WKK. Afterwards, he changed to Fraunhofer IZFP in Saarbrücken, Germany. From 2013 to 2018, he was a Senior Research Associate for the Chair of Non-Destructive Testing and Quality Assurance at Saarland University in Saarbrücken, Germany. In 2018, he became a Professor in the field of Materials Science and Materials Testing at the University of Applied Sciences Kaiserslautern (Hochschule
Kaiserslautern). His research is mainly focused on the use of non-destructive measurement techniques for the characterization of fatigue behavior and the fatigue life calculation of metallic and non-metallic materials in the LCF-, HCF- and VHCF-realm as well as for the evaluation of defects and inhomogeneities in the materials microstructure.

Prof. Dr. rer. nat. Monika Saumer was born in 1961. She graduated in Chemistry at the University in Bonn, Germany. After her PhD in Analytical Chemistry at the University of Karlsruhe, Germany, she worked at the Forschungszentrum Karlsruhe (now: Karlsruhe Institute of Technology = KIT) in the Institute of Microstructuring Technology. In 1998 she obtained a Professorship at the University of Applied Sciences Kaiserslautern/ Zweibrücken. Her research activities are focused on chemical processes for microfabrication including the electroplating of alloys, nanostructuring and related characterization methods.

Prof. Dr.-Ing. Patrick Klär, born in 1965, studied Material Sciences at The University of Saarland, Germany, from 1986 to 1991. Thereafter, he worked as a Scientific Assistant for nonlinear modelling and finite element simulations at the Chair of the Technical Mechanics at the University of Saarland and received his $\mathrm{PhD}$ degree in 1995. Subsequently, he worked as Deputy Head of the Development and Quality Assurance Department for a subsidiary company of the Saarstahl AG. From 1999 to 2000, he was Operating Chief for hard materials manufacturing at the subsidiary company of the Saarstahl AG. Since February 2000, he has been Professor for design and simulation of microsystems at the University of Applied Sciences Kaiserslautern. His working group works on the field of design and finite element simulation of microsystems and on the field of micro-cutting of microsystem materials and components. 